COMECHINGONIA. REVISTA DE ARQUEOLOGÍA

Número 15, 2011, pp. 65-92, Córdoba

ISSN 0326-7911

\title{
OCUPACIONES HUMANAS Y GRABADOS RUPESTRES DEL NORTE DE LA SIERRA DE VALLE FÉRTIL (PROVINCIA DE SAN JUAN)
}

\author{
Anahí $\operatorname{Re}^{1}$, M. Mercedes Podestá ${ }^{2}$ y Guadalupe Romero ${ }^{3}$ \\ ${ }^{1}$ CONICET - UBA - INAPL. anahire@inapl.gov.ar \\ ${ }^{2}$ INAPL. mercedespodesta@yahoo.com \\ ${ }^{3}$ INAPL. guada.romero.arq@gmail.com
}

Presentado el: 10/07/2011 - Aceptado 11/10/2011

\section{Resumen}

Se considera la problemática de las ocupaciones humanas prehispánicas del norte de la sierra de Valle Fértil (Provincia de San Juan), a partir del análisis del arte rupestre documentado. El objetivo de este trabajo es profundizar en la caracterización de los grabados de la región, haciendo hincapié en la zona de valles y quebradas. Así, se busca evaluar el potencial uso diferencial al interior de ésta, así como considerar su rol en una escala amplia. Se presenta la nueva información disponible al tiempo que se evalúan nuevas variables. Se revisa la tipología propuesta y se plantean subtipos más detallados a fin de sistematizar la diversidad morfológica observada. Asimismo, se exploran los patrones de distribución de las representaciones en distintas escalas, comparando los diferentes sitios así como la disposición al interior de los mismos. Por último, enfatizando la asociación del arte rupestre con otros tipos de evidencias arqueológicas, se busca brindar mayor información acerca de los posibles roles que tuvo el mismo dentro de la ocupación de la región.

Palabras claves: Arte rupestre, Sierra de Valle Fértil, Tipología, Distribución.

\begin{abstract}
This work considers the issue of prehispanic human occupations of the north of the Valle Fértil range (province of San Juan, Argentina) through the analysis of the rock art recorded. The aim of this paper is to deepen the characterization of the engravings of the region, focusing on the valley and ravine zone. By doing this, we seek to evaluate the potential differential use inside it as well as to consider its role on a greater scale. New information available is presented and novel variables are incorporated. The proposed tipology is revised and more detailed subtypes are suggested to systematize the morphological diversity observed. Also, the distribution patterns of the representations are explored on different scales, comparing the different sites as well as the disposition inside them. Finally, in emphasizing the association of the rock art with other kinds of archaeological evidence, we seek to provide more information about the possible roles that rock art had in the occupation of the region.
\end{abstract}

Keywords: Rock art, Valle Fértil Range, Tipology, Distribution. 


\section{Introducción}

En el presente artículo se considera la problemática de las ocupaciones humanas prehispánicas del norte de la sierra de Valle Fértil (Departamento Valle Fértil-Provincia deSan Juan), a partir del análisis del arte rupestre documentado. El estudio cuenta como punto de partida una primera caracterización de las representaciones rupestres de la región realizada por Re y colaboradores (2009). Se había detectado la presencia de motivos distribuidos en diversos sitios en la hoyada de Ischigualasto y en las estribaciones septentrionales de la sierra de Valle Fértil, zona denominada valles y quebradas interserranos. Se destacó que en esta última se registró la mayor cantidad y variedad de motivos rupestres. Re y colaboradores (2009) sostuvieron que los sitios con arte rupestre de la hoyada se relacionarían con lugares de paso mientras que los de valles y quebradas estarían asociados a espacios de mayor permanencia y de uso más intensivo. Por otra parte, se planteó de manera preliminar la presencia de diferencias al interior de esta última. La ocupación humana fue cronológicamente acotada entre los ca. 600 y 1500 años d.C. (Guráieb et al. 2010; Re et al. 2009).

De esta manera, el objetivo de este trabajo es profundizar en la caracterización del arte rupestre de la región, haciendo hincapié en la zona de valles y quebradas. En primer lugar, se presenta una descripción ambiental de la misma. Luego, se detallan los antecedentes de investigación disponibles tanto para el área de estudio como para otras cercanas. Seguidamente, se presenta la nueva información disponible -sitios y motivos recientemente relevados- al tiempo que se evalúan nuevas variables en el análisis. Se revisa la tipología propuesta y se plantean subtipos más detallados a fin de sistematizar la diversidad morfológica observada. Asimismo, se exploran los patrones de distribución de las representaciones en distintas escalas, comparando los diferentes sitios así como la disposición al interior de los mismos. Por último, se busca evaluar el potencial uso diferencial al interior de la zona de valles y quebradas del noreste de San Juan, así como considerar su rol en una escala amplia. Enfatizando la asociación del arte rupestre con otros tipos de evidencias arqueológicas, se busca brindar mayor información acerca de los posibles roles que tuvo el mismo dentro de la ocupación de la región. De esta manera, se explora la relación de las representaciones con los espacios nodales e internodales (sensu Nielsen 2006) definidos en diferentes escalas espaciales.

\section{Caracterización ambiental del área de estudio}

La sierra de Valle Fértil se ubica en el departamento homónimo en el noreste de la provincia de San Juan (Figura 1). El área de investigación incluye sus estribaciones septentrionales y la hoyada de Ischigualasto, mejor conocida como Valle de la Luna, colindante con la provincia de La Rioja. La misma presenta una superficie de $1400 \mathrm{~km} 2$ y se corresponde, en gran medida, con el ámbito del Parque Provincial Ischigualasto y parte de su área de amortiguación. Geográficamente, la sierra de Valle Fértil se continúa al sur en la sierra de La Huerta, constituyendo la frontera suroccidental de las Sierras Pampeanas. Hacia el oeste de la sierra se encuentra la gran llanura del valle del río Bermejo. Por último, el límite noreste del área de investigación lo constituyen las Barrancas Coloradas, incluidas en el Parque Nacional Talampaya, provincia de La Rioja (Figura 1).

En lo referido al clima, la región de estudio está incluida en la gran Diagonal Árida Sudamericana (Pereyra 2000). De tipo continental, predominantemente seco con marcada amplitud térmica. Las escasas precipitaciones, entre $250-400 \mathrm{~mm}$ anuales, se concentran 
exclusivamente en el período estival. De esta manera, los ríos de la región tienen un régimen de fuerte estacionalidad caracterizado por intensas escorrentías de corta duración. Estas características climático-ambientales, que presentan variaciones locales, permitieron distinguir dos zonas ecológicas diferenciadas (Re et al. 2009) (Figura 1): por un lado, la amplia hoyada de Ischigualasto y, por el otro, los valles y quebradas interserranos de las estribaciones del norte de la sierra de Valle Fértil, siendo esta última abordada en profundidad en el presente trabajo.

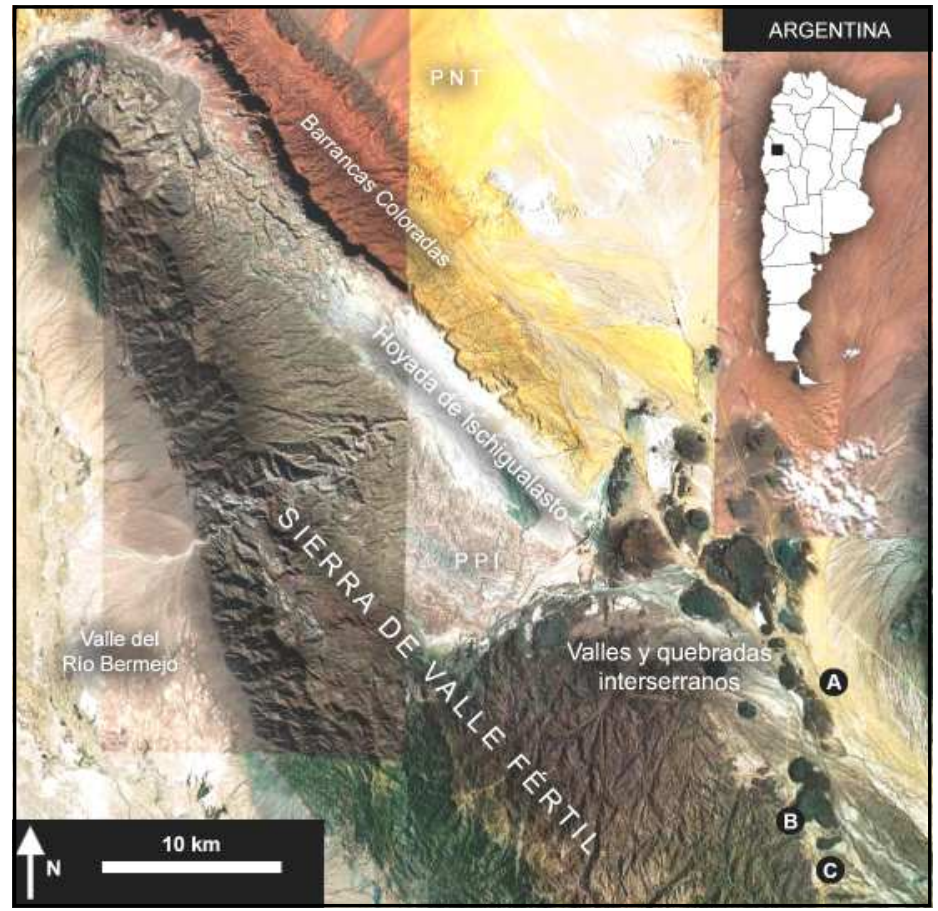

Figura 1. Ubicación del área de estudio.

Referencias: $P$ PI = Parque Provincial Ischigualasto, $P N T=$ Parque Nacional Talampaya, $A=$ Los Baldecitos, $B=$ Los Rincones, $C=$ Balde del Rosario.

Los valles y quebradas de la sierra de Valle Fértil

La sierra de Valle Fértil es un conjunto serrano de tipo asimétrico con una pendiente predominante de oeste a este (Suvires 2000). La vertiente occidental es la más abrupta e inclinada mientras que hacia el oriente el descenso es más suave. Tiene una altitud promedio que varía entre los ca. 1200 a $1800 \mathrm{msnm}$. Cauces temporarios de poca profundidad, como por ejemplo, el río El Durazno, drenan la sierra en sentido oeste-este (Figura 2).

La aridez general de la región se atempera en el ámbito serrano, fomentando el cambio de condiciones naturales de clima desértico a una variedad subhúmeda en algunos sectores del mismo (Suvires 2000). Al correr en sentido noroeste-sureste, conforma una barrera a los vientos húmedos procedentes del Atlántico, motivo por el cual éstos descargan las precipitaciones en la vertiente oriental del cordón montañoso. Así, las precipitaciones medias anuales varían entre los 300 y $400 \mathrm{~mm}$ con acentuadas oscilaciones en el sector central de la sierra de Valle Fértil, creciendo la intensidad de las mismas hacia el interior de la sierra 
(Ardissone y Grondona 1953; Pereyra 2000). Biogeográficamente está representado el Dominio Chaqueño con el Monte como provincia dominante (Morrone 2005), no obstante se observan diferencias internas relacionadas con la topografía.

Las diferentes altimetrías de la sierra influyen en la temperatura y la dinámica local de la ecología, controlando el desarrollo de una extensa y larga faja pedemontana que presenta características diferenciales a las observadas en el cordón montañoso (Lochbaum 1993). Por un lado, la faja pedemontana o piedemonte está conformada por los sectores más bajos. Aquí, los espacios son más abiertos o de tipo rincón, denominación local de las profundas entradas con amplios recodos en forma de $U$ que se describen en la parte baja del faldeo (Figura 2). En la actualidad, hacia el este de la faja pedemontana, se ubican las localidades de Los Baldecitos, Los Rincones y Balde del Rosario (Figura 1). Estas instalaciones humanas aprovechan para su subsistencia los cursos de agua temporarios que drenan la sierra y proveen de agua para el consumo, el riego y la ganadería durante el verano (Re et al. 2009). Por el otro lado, el cordón montañoso comprende las mayores altitudes de la sierra de Valle Fértil. Este sector presenta una topografía diversa con predominancia de abras que comunican quebradas y bolsones interiores de la sierra.

A los fines de este trabajo se considerará la distribución de los sitios arqueológicos en el piedemonte y en el cordón montañoso de acuerdo un criterio altitudinal. De esta manera, el primero estaría comprendido entre los 1200 a 1300 msnm y el segundo arriba de los 1300 msnm.

\section{Antecedentes de investigación}

En términos generales, las investigaciones arqueológicas de la provincia de San Juan se han focalizado en el estudio de los valles preandinos y precordilleranos como los de Iglesia y Calingasta, con breves menciones al arte rupestre (ver por ejemplo Gambier 2000). En lo referido a esta línea de evidencia, Consens (2003) estima que la variabilidad de diseños observada en la provincia de San Juan imposibilita la elaboración de tipologías. No obstante, en tiempos recientes ésta ha sido abordada en algunos trabajos (García et al. 2011; López y García 2011; Riveros 2010, 2011; Riveros y Varela 2001).

Hacia el norte del área bajo análisis, se ha descripto la presencia de evidencias de ocupación prehispánica y, en particular, de arte rupestre en el actual Parque Nacional Talampaya en la provincia de La Rioja (Ferraro 2005; Giordano y Gonaldi 1991). Se ha planteado que éstas deben ser consideradas en el marco de la arqueología del noroeste argentino, constituyendo una zona periférica. Los grabados han sido asignados cronológicamente a los períodos Agroalfarero Medio y Tardío (Ferraro 2005). En el sur de la misma provincia, a $80 \mathrm{~km}$ al noreste del área de estudio, se ha destacado la cantidad y diversidad de motivos rupestres en el sitio Palancho (Falchi et al. en este volumen), así como la presencia en menores densidades de similares representaciones en Los Colorados (Falchi y Torres 2010; INAPL 2009). Las distintas pátinas y superposiciones de Palancho permitieron proponer diferentes momentos de ejecución (Falchi et al. en este volumen).

Se cuenta asimismo con antecedentes más próximos al área de estudio. El primero de ellos refiere al arte rupestre del sur de la sierra de Valle Fértil y el norte de la sierra de La Huerta, donde se mencionan dos sitios con grabados y la presencia de gran cantidad de morteros (Ardissone y Grondona 1953). Posteriormente, Schobinger y Gradin (1985: 77) plantearon 


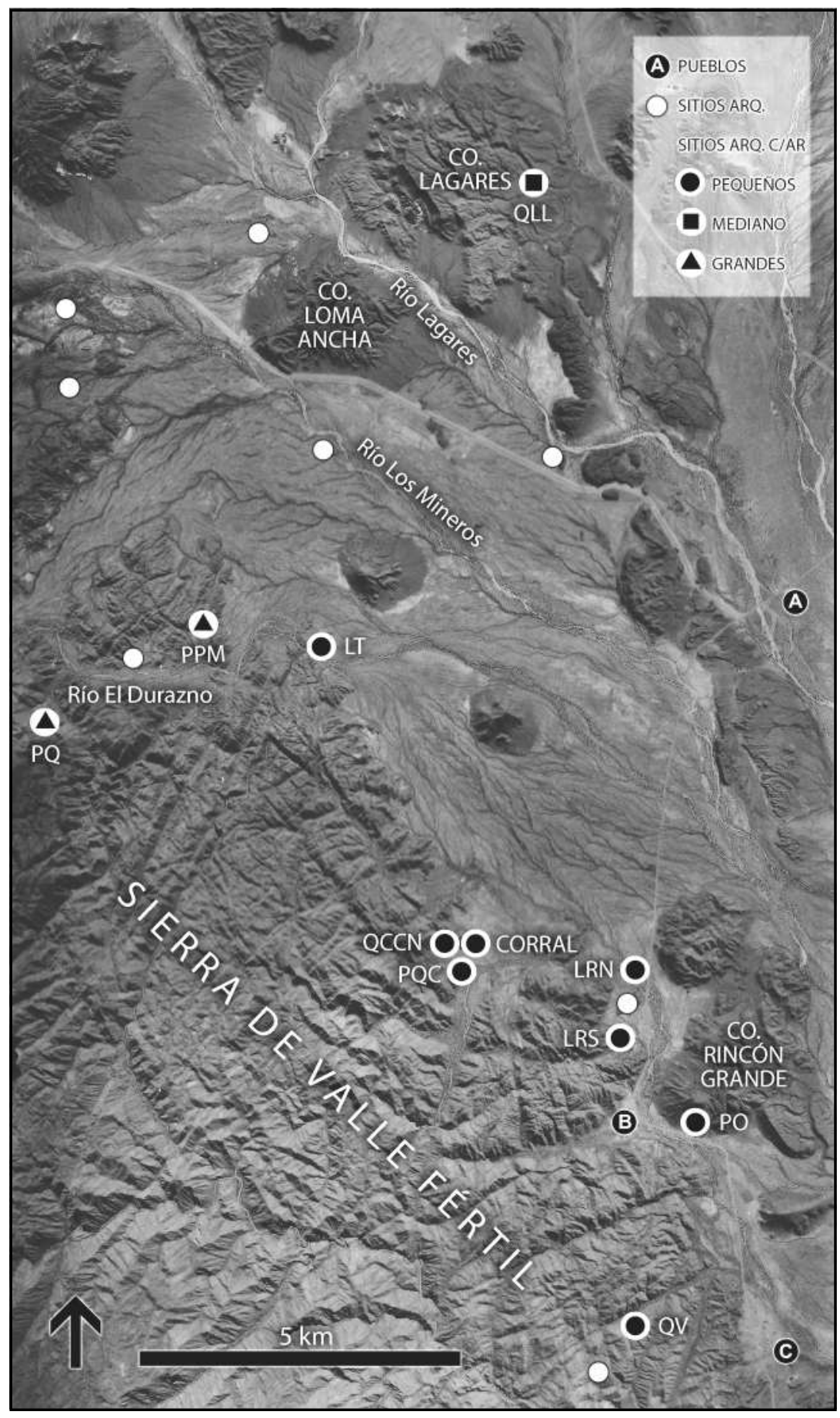

Figura 2. Sitios arqueológicos en la zona de valles y quebradas.

Referencias: $A R Q .=$ Arqueológicos, $C / A R=$ con arte rupestre, $C O .=$ cerro, $A=$ Los Baldecitos, $B=$ Los Rincones, $C=$ Balde del Rosario. 
la existencia de una "tendencia abstracta más o menos compleja" en el arte rupestre de la región. En tiempos más recientes, los trabajos de Cahiza (2006-2007, 2007), también en el sur de la sierra de Valle Fértil y el norte de La Huerta, dieron a conocer una concentración de sitios arqueológicos con dataciones entre 230 y 1650 años d.C. (García Llorca et al. 2010). Siete de ellos presentan grabados rupestres en asociación a morteros comunales y áreas caracterizadas como canteras y talleres de extracción de materias primas y formas-base. Así, este autor señala la relación espacial del arte rupestre con espacios de actividad doméstica y, por otro lado, destaca su posible función como marcadores del tránsito interserrano.

Las investigaciones en que se enmarca el presente artículo se iniciaron en 1999 en la mencionada hoyada de Ischigualasto. Previamente, se contaba con breves referencias a las ocupaciones humanas prehispánicas (Gambier 2000; Monetta y Mordo 1995-1996) de las cuales sólo algunas mencionaban el arte rupestre (Riveros y Varela 2001; Sanchidrián Torti y Márquez Alcántara 1998). En un principio los trabajos realizados por el equipo se orientaron a la caracterización del arte rupestre de momentos históricos (Podestá y Rolandi 2000, 2001; Podestá et al. 2006, 2011). No obstante, los trabajos de campo evidenciaron la presencia de una importante ocupación prehispánica, tanto en la hoyada como en las estribaciones septentrionales de la sierra de Valle Fértil (Rolandi et al. 2003). De esta manera, se comenzó el estudio de las diversas líneas de evidencia, incluyendo la tecnología lítica y cerámica, estructuras de piedra (algunas de piedras de colores) y arte rupestre (Guráieb et al. 2007, 2010; Re et al. 2009). En la zona de valles y quebradas se llevó a cabo un estudio del material lítico y cerámico de dos sitios de superficie con presencia de arte rupestre: La Toma (LT) y Puerta Quebrada de las Casas (PQC) (Guráieb et al. 2010) (Figura 2). Cronológicamente fueron ubicados dentro del Período Agroalfarero Medio sobre la base de la presencia de cerámica decorada de estilo La Aguada y de dos fechados obtenidos por termoluminiscencia (Tabla 1). Sin embargo, se contempla que las fechas obtenidas son sólo indicativas de una cronología posiblemente mucho más extensa.

En lo referido al arte rupestre prehispánico de la región, Re y colaboradores (2009) realizaron una primera caracterización tanto de los motivos hallados en la zona de la hoyada como en la de valles y quebradas. Se planteó la existencia de similitudes y diferencias entre las representaciones registradas en ambas zonas. Los sitios analizados fueron clasificados según la cantidad de motivos diferenciándose sitios pequeños (1 a 50 motivos), medianos (51 a 150) y grandes (más de 151). En la hoyada se describió la presencia de cuatro sitios, tres pequeños y uno mediano con un total de 195 motivos. Los soportes utilizados son bloques y paredes de arenisca, habiéndose empleado distintas técnicas de grabado, principalmente picado. Por otra parte, en los valles y quebradas se identificaron nueve sitios (siete pequeños y dos grandes), sumando 603 motivos. La mayoría de los soportes son bloques de granito de dimensiones variables, utilizándose paredes sólo en uno de los sitios. Se observó que la totalidad de los motivos fueron realizados por picado siendo posible que la dureza del soporte haya determinado el empleo de esta única técnica.

En ambas zonas se observó el predominio de los abstractos, prevaleciendo los círculos con línea y las líneas sinuosas. En menores porcentajes, se registraron las líneas quebradas, las cruces de contorno curvilíneo y los geométricos complejos. Entre los figurativos se relevaron figuras humanas, camélidos y tridígitos, así como huellas de felino y humanas. Como diferencias se planteó que en la hoyada se halla una mayor cantidad de figurativos, encontrándose presentes algunos tipos no registrados en valles y quebradas, y la existencia de abstractos de diseños complejos como pirámides. Por otra parte, en los valles y quebradas 
se observó una mayor representación de círculos y óvalos en todas sus variantes y una mayor variedad de tipos abstractos. A partir de la escasez de superposiciones de motivos y la poca diferenciación de las pátinas de los grabados, se planteó una ejecución temporalmente acotada de los mismos. Se sugirió que la misma pudo estar comprendida entre ca. 600 y 1500 años d.C. (períodos Agroalfarero Medio y Tardío) sobre la base de los tiestos cerámicos y fechados del área de estudio así como las cronologías propuestas para otras cercanas (Re et al. 2009).

Re y colaboradores (2009) sostuvieron que los sitios con arte rupestre de la hoyada se relacionan con lugares de paso mientras que los de valles y quebradas están asociados a espacios de mayor permanencia y de uso más intensivo. Por otra parte, se planteó de manera preliminar la presencia de diferencias al interior de esta última. De esta manera, en este trabajo se propone profundizar la caracterización del arte rupestre de la región, haciendo hincapié en la zona de valles y quebradas.

\section{La muestra}

En el análisis del arte rupestre de la región, en este trabajo se incorporaron nuevos motivos a la muestra de los sitios ya conocidos y dos nuevos sitios producto de relevamientos más recientes. De esta manera, el total de la muestra disponible al momento asciende a 747 motivos en 158 soportes distribuidos en 11 sitios (Tabla 1 y Figura 2).

\section{Tipología utilizada}

De acuerdo a los objetivos de este trabajo, en este acápite se presentan los resultados producto de la profundización en el análisis de la variabilidad morfológica de los grabados de la zona de valles y quebradas. En primera instancia, se revisó la tipología propuesta en la aproximación inicial realizada por Re y colaboradores (2009), agrupando algunos tipos, diferenciando otros y modificando algunas denominaciones. Los motivos relevados fueron clasificados en categorías generales tales como abstractos, zoomorfos, antropomorfos e indeterminados. Posteriormente, éstos fueron asignados a diferentes tipos de motivos dentro de cada una de estas categorías, identificando en esta oportunidad: 22 tipos abstractos, 4 tipos zoomorfos y 3 tipos antropomorfos (Figuras 3 y 4 ).

Asimismo, en esta revisión más detallada se observó una gran variabilidad morfológica al interior de la mayor parte de los tipos de motivos considerados, principalmente, dentro de los abstractos. De esta manera, se planteó la necesidad de evaluar la diversidad en ciertos tipos de motivos mediante la creación de subtipos. El criterio utilizado para definir estos subtipos refiere principalmente a la variabilidad morfológica detectada en los diseños de los motivos, reflejada generalmente en una mayor o menor complejidad y/o en diferente inversión de trabajo en su ejecución. Éstos se diferenciaron al interior de 12 tipos abstractos, en los que la cantidad de motivos justificaba su definición. Fueron denominados mediante letras (por ejemplo A o B) (Figuras 3 y 4 y Tablas 2 y 3). En la mayoría de los casos se identificaron dos subtipos mientras que los restantes presentan tres y cinco (Tabla 6).

Dado que no existe una única tipología consensuada entre los distintos investigadores y las dificultades específicas que implica esta tarea en el caso del arte rupestre (ver por ejemplo Re 2011), en las tablas presentadas se explicitan los rasgos morfológicos seleccionados en esta investigación para caracterizar cada tipo y subtipo de motivo (Tablas 2 y 3). 


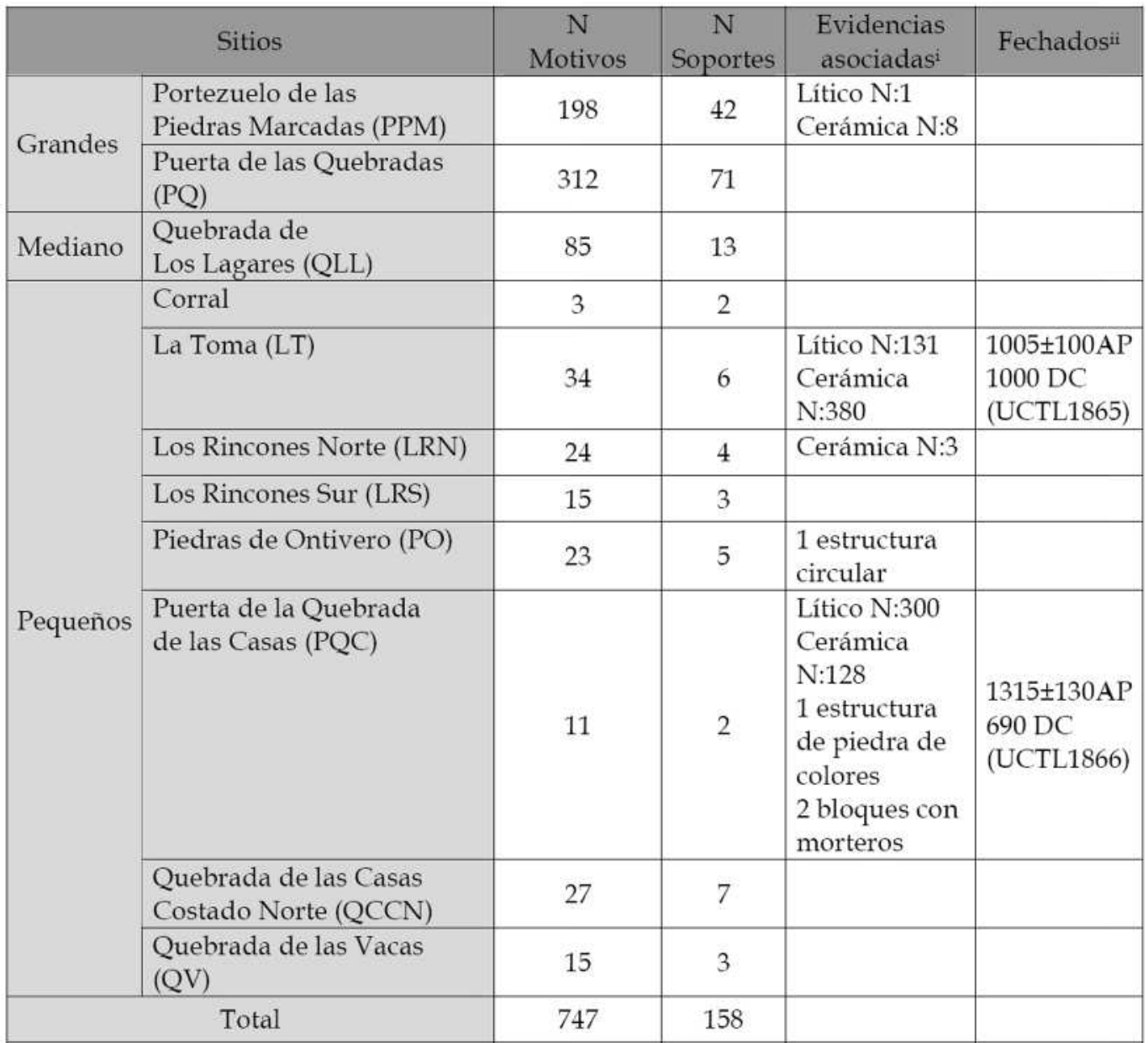

Tabla 1. Sitios con arte rupestre del norte de la sierra de Valle Fértil ordenados por tamaño (cantidad de motivos) (datos modificados y actualizados de Re et al. 2009).

\section{Frecuencia de tipos y subtipos en el norte de la sierra de Valle Fértil}

Cuando se considera el área objeto de este artículo en su conjunto, a pesar de la incorporación de nueva información, se mantuvieron las tendencias observadas previamente por Re y colaboradores (2009) en relación a la proporción de categorías de motivos representados. Siguen predominando los abstractos (N: 628, 84,07\%) por sobre los zoomorfos (N: 54, 7,23\%), antropomorfos (N: 12, 1,61\%) e indeterminados (N: 53, 7,10\%) (Tabla 4).

Entre los abstractos, en mayores frecuencias se ubican los círculos $(12,68 \%)$ y las líneas sinuosas $(10,09 \%)$ seguidos por las líneas quebradas $(9,37 \%)$ y los círculos con línea $(9,22 \%)$ (Tabla 5 y Figura 5a, c y d). En menores porcentajes se registran tipos tales como geométrico complejo $(6,92 \%)$, cruz de contorno curvilíneo $(5,04 \%)$ y, con iguales porcentajes, círculo con línea interna y línea curva $(4,32 \%)$. Asimismo, se encuentran representadas otras formas geométricas simples (círculos concéntricos, cruces, figuras sinuosas, líneas rectas, semicírculos y trazos) y tipos de características particulares tales como los cuadriláteros con diseño interno, las líneas en $\mathrm{V}$ con extremos diferenciados y las líneas con extremos diferenciados. Como se 


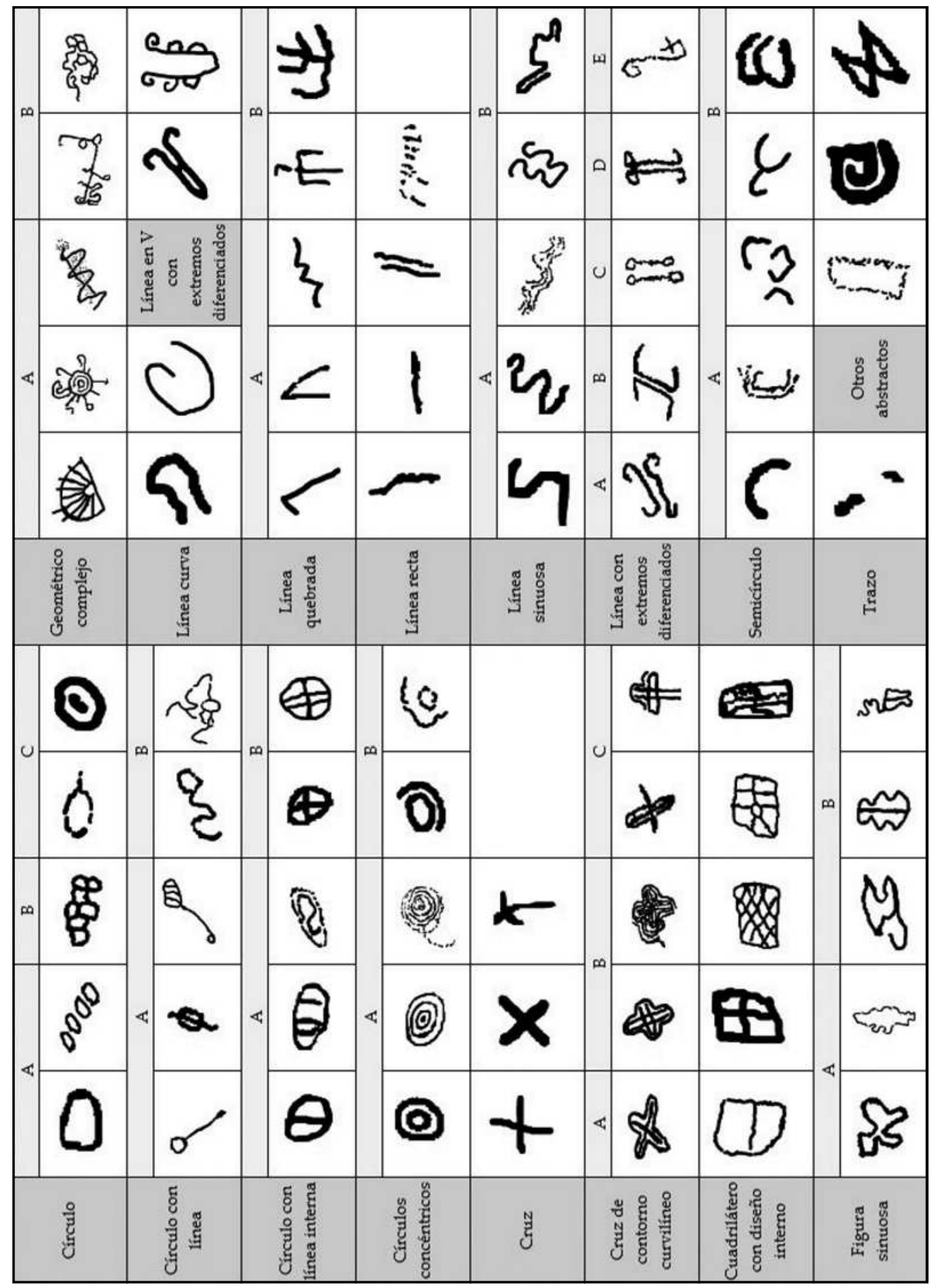

Figura 3. Tipos y subtipos de motivos abstractos definidos en el área seleccionada. 


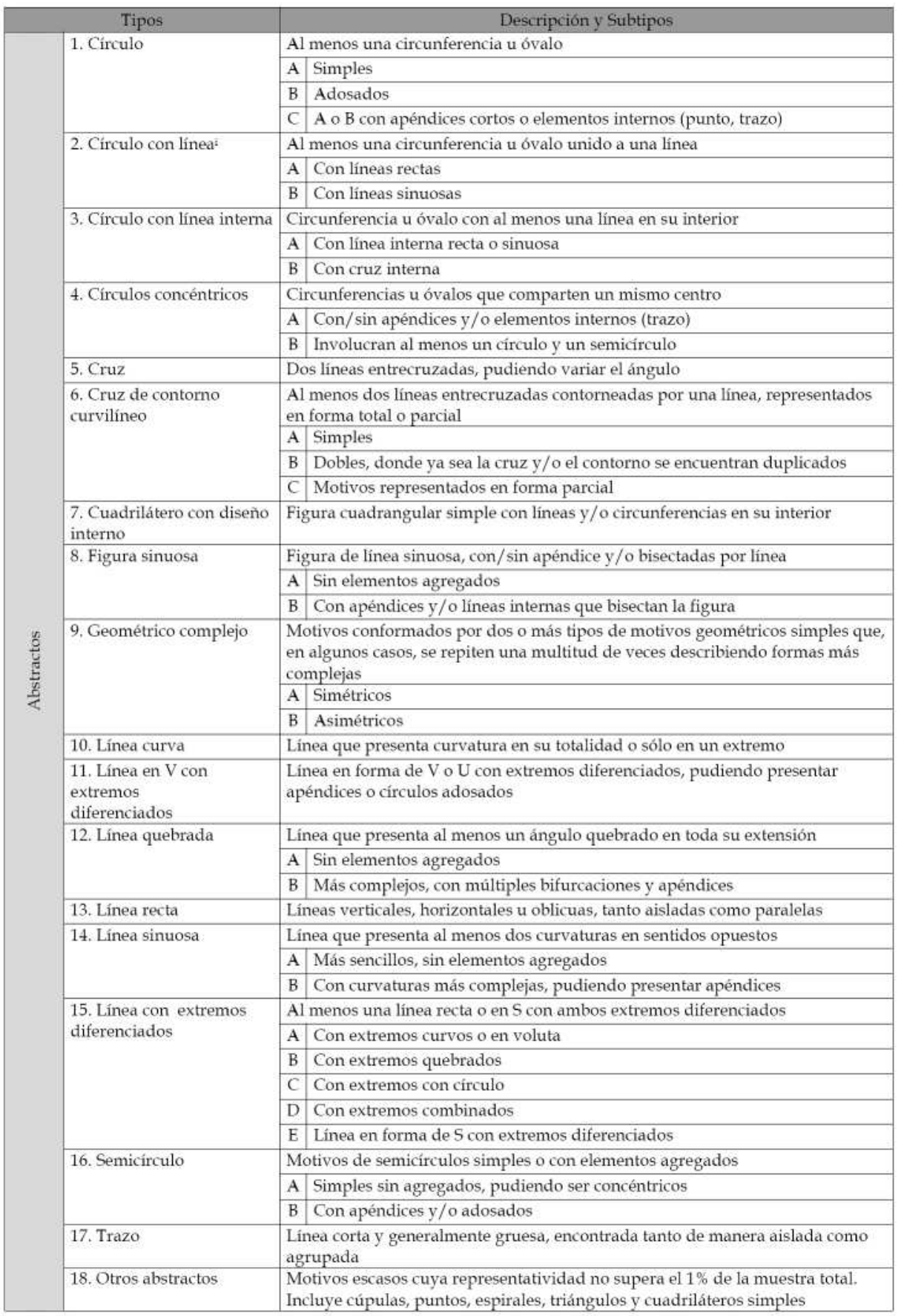

Tabla 2. Tipos y subtipos de motivos abstractos definidos en el área seleccionada.

mencionó anteriormente, se observó una gran variabilidad morfológica al interior de gran parte de los tipos abstractos. Para evaluarla en forma sistemática, se diferenciaron subtipos, identificándose en la mayoría de los casos dos y en los restantes tres y cinco (Figura 3 y Tabla 6). Respecto de las frecuencias, en casi todos ellos un subtipo concentra más del $50 \%$ 


\begin{tabular}{|c|c|c|}
\hline \multicolumn{2}{|r|}{ Tipo } & Descripción y Subtipos \\
\hline \multirow{4}{*}{ 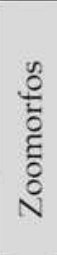 } & 1. Camélido & Siluetas asignables a camélidos silvestres o domesticados \\
\hline & 2. Lagartija & Representaciones asignadas a variedades del género Liolnemus \\
\hline & $\begin{array}{l}\text { 3. Pisada o rastro } \\
\text { de ave }\end{array}$ & $\begin{array}{l}\text { Motivos tridígitos que representarían pisadas de aves como el suri } \\
\text { (Rhea pennata) u otras }\end{array}$ \\
\hline & $\begin{array}{l}\text { 4. Pisada o rastro } \\
\text { de felino }\end{array}$ & Motivos asignados a huellas de puma (Felis concolor) \\
\hline \multirow{3}{*}{ 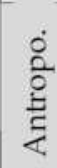 } & 1. Figura humana & Siluetas asignables a la figura humana \\
\hline & $\begin{array}{l}\text { 2. Pisada o rastro } \\
\text { de humano }\end{array}$ & Motivos asignados a huellas humanas \\
\hline & 3. Rostro & Representaciones asignadas a rostros humanos \\
\hline
\end{tabular}

Tabla 3. Tipos de motivos figurativos definidos en el área considerada.

Referencias: Antropo. $=$ Antropomorfos.

de los motivos, como se observa en los círculos (A: 60,23\%) y los geométricos complejos (B: 72,92\%). Por otro parte, sólo en los círculos con línea, las figuras sinuosas y las líneas con extremos diferenciados se observa una distribución homogénea entre los subtipos identificados (Tabla 6).

Respecto de los figurativos, los zoomorfos son la categoría más numerosa (Tablas 4 y 5). Se registraron casos de representaciones tanto de siluetas como de pisadas de animales. Entre las primeras se cuentan las lagartijas $(0,29 \%)$ y los camélidos $(0,86 \%)$ (Figura 5 c y d). Como se observó en el análisis preliminar (Re et al. 2009), estos últimos son en su totalidad esquemáticos y presentan una importante estandarización. Mayoritariamente fueron representados en forma aislada salvo en el caso del bloque 28 del sitio PQ donde el motivo está conformado por dos camélidos en hilera.

\begin{tabular}{|c|c|c|c|c|c|c|c|}
\hline $\begin{array}{l}\text { Tamaño } \\
\text { de sitios }\end{array}$ & Sitio & Abstractos & Zoomorfos & $\begin{array}{l}\text { Antropo } \\
\text { morfos }\end{array}$ & Indet. & $\begin{array}{c}\text { Total } \\
\%\end{array}$ & $\begin{array}{c}\text { Total } \\
\mathrm{N}\end{array}$ \\
\hline \multirow{8}{*}{ Pequeños } & Corral & $100 \%$ & & & & $100 \%$ & 3 \\
\hline & LT & $82,35 \%$ & & $8,82 \%$ & $8,82 \%$ & $100 \%$ & 34 \\
\hline & LRN & $87,50 \%$ & & & $12,50 \%$ & $100 \%$ & 24 \\
\hline & LRS & $60,00 \%$ & $13,33 \%$ & $6,67 \%$ & $20,00 \%$ & $100 \%$ & 15 \\
\hline & $\mathrm{PO}$ & $95,65 \%$ & $4,35 \%$ & & & $100 \%$ & 23 \\
\hline & PQC & $81,82 \%$ & & & $18,18 \%$ & $100 \%$ & 11 \\
\hline & $\mathrm{QCCN}$ & $81,48 \%$ & & $3,70 \%$ & $14,81 \%$ & $100 \%$ & 27 \\
\hline & QV & $100 \%$ & & & & $100 \%$ & 15 \\
\hline \multicolumn{2}{|c|}{ Total Pequeños } & $84,87 \%$ & $1,97 \%$ & $3,29 \%$ & $9,87 \%$ & $100 \%$ & 152 \\
\hline Mediano & QLL & $82,35 \%$ & $8,24 \%$ & $2,35 \%$ & $7,06 \%$ & $100 \%$ & 85 \\
\hline \multicolumn{2}{|c|}{ Total Mediano } & $82,35 \%$ & $8,24 \%$ & $2,35 \%$ & $7,06 \%$ & $100 \%$ & 85 \\
\hline \multirow{2}{*}{ Grandes } & PPM & $82,32 \%$ & $9,09 \%$ & & $8,59 \%$ & $100 \%$ & 198 \\
\hline & PQ & $85,26 \%$ & $8,33 \%$ & $1,60 \%$ & $4,81 \%$ & $100 \%$ & 312 \\
\hline \multicolumn{2}{|c|}{ Total Grandes } & $84,12 \%$ & $8,63 \%$ & $0,98 \%$ & $6,27 \%$ & $100 \%$ & 510 \\
\hline \multicolumn{2}{|c|}{ TOTAL } & $84,07 \%$ & $7,23 \%$ & $1,61 \%$ & $7,10 \%$ & $100 \%$ & 747 \\
\hline
\end{tabular}

Tabla 4. Categorías de motivos presentes en el área. Referencias: Indet. = Indeterminados. 


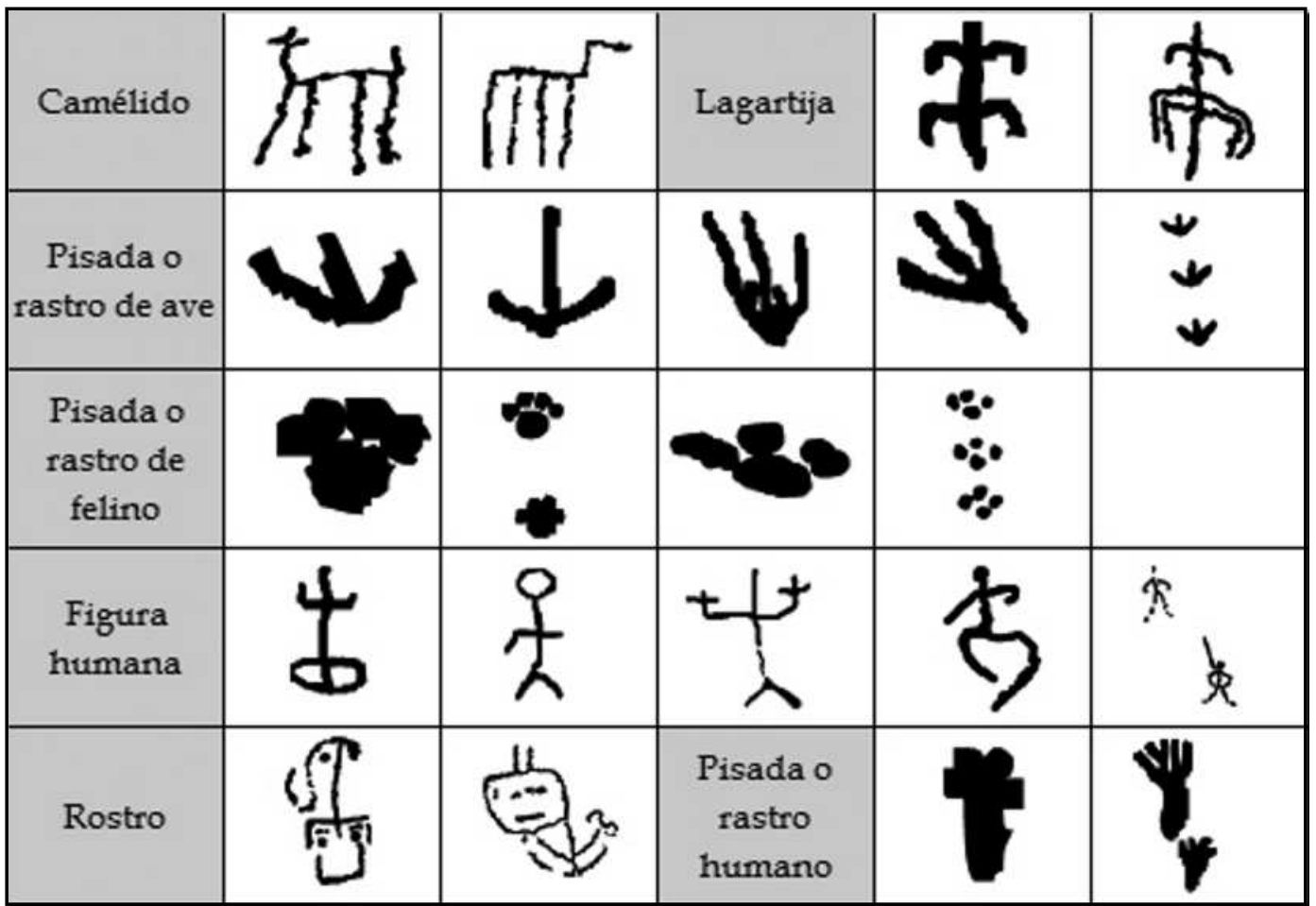

Figura 4. Tipos de motivos figurativos definidos en el área considerada.

Respecto de las huellas, se observa el predominio de las pisadas o rastros de ave $(5,48 \%)$ por sobre las pisadas o rastros de felino (1,15\%) (Figura 5a, c y d). De esta manera, los tridígitos constituyen el tipo figurativo más representado dentro de la zona estudiada a pesar de lo cual presentan escasa variabilidad morfológica (Figura 5a, c y d). Por otra parte, los antropomorfos constituyen la categoría figurativa menos representada (Tablas 4 y 5). A pesar de encontrarse en baja frecuencia, las figuras humanas $(1,15 \%)$ presentan una enorme variabilidad interna (Figura $5 \mathrm{~b}$ ). Los tipos restantes, rostro y pisada o rastro humano, se registran en bajos porcentajes $(0,29 \%)$.

Por último, se revisaron las superposiciones previamente identificadas en esta zona (Re et al. 2009) que ascienden a un total de 24 casos. De modo general, los motivos involucrados son en su mayoría abstractos predominando las variedades de los tipos de motivos círculos y líneas aunque hay algunos ejemplos de motivos geométricos complejos, cruces de contorno curvilíneo y líneas con extremos diferenciados. Entre los figurativos, los únicos motivos involucrados son 3 tridígitos y 1 camélido. En 12 superposiciones se pudo resolver el orden de ejecución de los motivos (ver ejemplo en Figura 5a). Interesa destacar que en tres casos se observó que los tridígitos se ubican en la posición superior. 


\section{Distribución de los motivos}

Comparación inter-sitio

Como se planteó previamente, otro objetivo de este artículo es considerar la distribución espacial de los motivos rupestres en la zona de valles y quebradas. Se observó que éstos presentan una distribución heterogénea, ya que se encuentran agrupados en 11 sitios (Figura 2). Además, como ya fuera observado por Re y colaboradores (2009), la cantidad de motivos registrados en cada uno de ellos es variable. Así, se diferencian ocho sitios pequeños (1 a 50 motivos), uno mediano (51 a 150 motivos) y dos grandes (más de 151 motivos) (Figura 2 y Tabla 1$)$.

Las tendencias observadas por Re y colaboradores (2009) en cuanto a la ubicación de los sitios pequeños y grandes siguen siendo evidentes. Los pequeños se ubican en la faja pedemontana a una altura sobre el nivel del mar entre los 1200 y $1300 \mathrm{~m}$. La mayoría están localizados en los cursos de agua temporarios que bajan hacia el llano y circunscriptos en

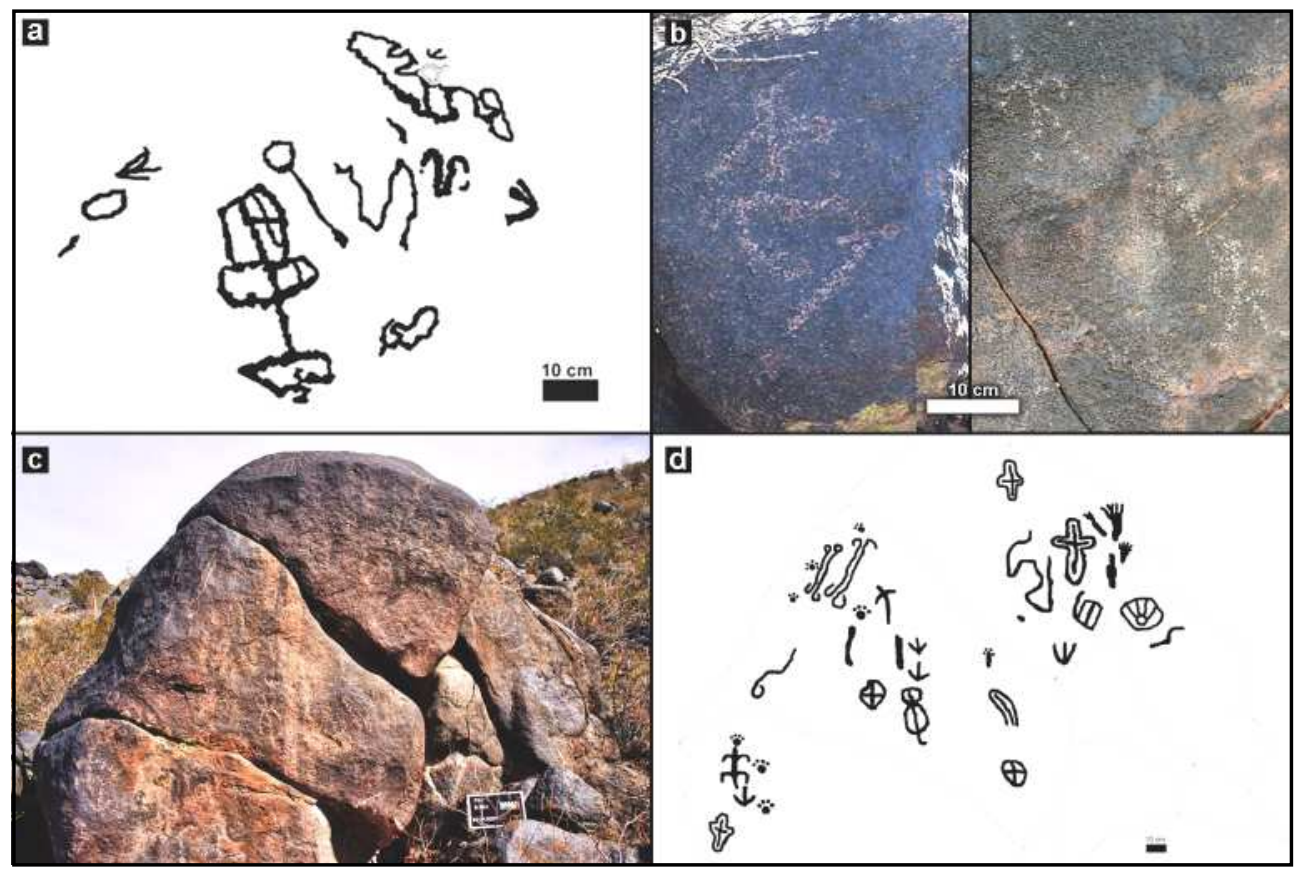

Figura 5. $a=$ calco del bloque 8 (cara B) del sitio PQ. Se indica superposición en color más claro, $b=$ ejemplos de figuras humanas de los sitios QCCN (izquierda) y QLL (derecha), c y $d=$ foto y calco del bloque 28 (cara A) del sitio PQ.

ambientes de tipo rincón. En forma excepcional, dos de estos sitios presentan características ambientales que difieren de las antes mencionadas. Uno de ellos es PO, que se ubica en una lomada que permite una visión ininterrumpida del terreno circundante. El otro sitio es QV que se encuentra en una pequeña quebrada.

El único sitio mediano identificado (QLL) se ubica en el extremo septentrional de la región estudiada, a $1340 \mathrm{msnm}$ en las inmediaciones del cerro Lagares. A su vez, se distingue del resto de los sitios analizados por ser el único caso que registra el uso de paredes para la 


\begin{tabular}{|c|c|c|c|c|c|c|c|c|c|c|c|c|c|c|c|c|c|c|c|c|c|c|c|c|c|c|c|c|c|c|}
\hline స్ & & 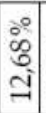 & ๙ิ๋ & 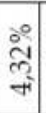 & 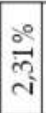 & ஃ̊ & 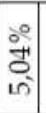 & $\begin{array}{l}02 \\
\stackrel{2}{0} \\
\infty \\
-1\end{array}$ & 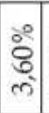 & $\begin{array}{l}\stackrel{\circ}{\circ} \\
\text { مे }\end{array}$ & 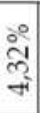 & 足 & $\begin{array}{l}20 \\
1 \\
0 \\
0 \\
0\end{array}$ & $\begin{array}{l}\circ \\
\infty \\
\infty \\
i \\
i\end{array}$ & ¿̊ & $\mid \begin{array}{l}\stackrel{2}{2} \\
\text { in }\end{array}$ & 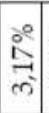 & 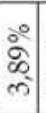 & $\begin{array}{l}\text { ते } \\
\text { ते } \\
\text { ते }\end{array}$ & $\begin{array}{l}\stackrel{0}{9} \\
\stackrel{2}{2}\end{array}$ & $\begin{array}{l}0 \\
\circ \\
\circ \\
0\end{array}$ & $\begin{array}{l}\text { ते } \\
\text { ते } \\
0\end{array}$ & $\begin{array}{c}\text { ஃ̊ } \\
9 \\
\text { ஸी } \\
10\end{array}$ & 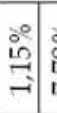 & $\begin{array}{ll}\circ \\
\infty \\
0 \\
\\
\end{array}$ & 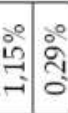 & ç & $\stackrel{-1}{2}$ & ஓి & छే \\
\hline$\frac{\tilde{q}}{\tilde{z}}$ & $a$ & 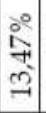 & ڤั & 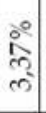 & 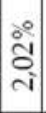 & ㅇํㄹ & $\begin{array}{l}\stackrel{\circ}{\mathrm{N}} \\
\mathrm{1}\end{array}$ & $\begin{array}{l}\stackrel{2}{2} \\
\grave{\vdots} \\
\text { i }\end{array}$ & $\stackrel{\circ}{\stackrel{\circ}{*}}$ & 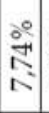 & $\begin{array}{l}\text { iั } \\
\text { i் } \\
10\end{array}$ & $\begin{array}{c}\stackrel{0}{1} \\
\text { ปे } \\
\text { î }\end{array}$ & $\frac{2}{2}$ & 总 & $\begin{array}{l}\circ \\
0 \\
0 \\
0\end{array}$ & $\begin{array}{l}\therefore \\
0 \\
8 \\
\infty \\
\infty\end{array}$ & 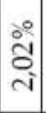 & $\begin{array}{l}\text { ¿े } \\
\text { సे } \\
\text { है }\end{array}$ & ㅇํำ & 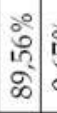 & 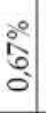 & 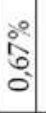 & $\begin{array}{c}0 \\
8 \\
0 \\
0\end{array}$ & 㤐 & \begin{tabular}{l|l}
$\stackrel{0}{2}$ \\
$\stackrel{i}{\circ}$ \\
$\infty^{\circ}$
\end{tabular} & \begin{tabular}{l|l}
$\circ$ & 0 \\
0 & 0 \\
0 & 0 \\
0
\end{tabular} & 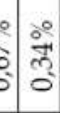 & 웅 & 융 & ते \\
\hline ज्ञ & 育 & 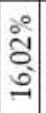 & ठำ & $\begin{array}{l}\stackrel{0}{ } \\
\grave{\lambda} \\
\infty\end{array}$ & 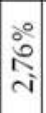 & : & $\begin{array}{l}\circ \\
\vdots \\
0 \\
\omega^{2}\end{array}$ & 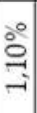 & $\begin{array}{l}\stackrel{0}{\circ} \\
\stackrel{-}{-1}\end{array}$ & $\stackrel{\circ}{7}$ & 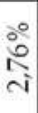 & & $\begin{array}{l}\vdots \\
\stackrel{2}{0} \\
0 \\
0\end{array}$ & 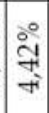 & $\begin{array}{c}\stackrel{0}{10} \\
\stackrel{7}{a} \\
\cdots\end{array}$ & $\begin{array}{l}\circ \\
\stackrel{0}{3} \\
\infty^{2}\end{array}$ & $\begin{array}{l}0 \\
\text { రిక్} \\
0 \\
0\end{array}$ & ؛ำ & $\begin{array}{c}\circ \\
\stackrel{0}{2} \\
\omega^{2}\end{array}$ & $\begin{array}{l}\circ \\
8 \\
8\end{array}$ & 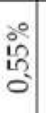 & & $\begin{array}{l}\stackrel{0}{2} \\
\text { స్ }\end{array}$ & $\stackrel{\circ}{\stackrel{\Xi}{-}}$ & $\begin{array}{l}\text { वे } \\
\text { बे' } \\
\text { बे }\end{array}$ & & & & $\begin{array}{l}\stackrel{0}{8} \\
\stackrel{-}{-1}\end{array}$ & $\vec{\infty}$ \\
\hline 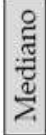 & $\bar{a}$ & $\begin{array}{l}\stackrel{0}{ } \\
\stackrel{2}{0} \\
\infty \\
\overbrace{}^{2}\end{array}$ & $\begin{array}{l}\circ \\
\vdots \\
\infty \\
\text { ले }\end{array}$ & \begin{tabular}{l}
$\stackrel{0}{\circ}$ \\
\multirow{-}{-}{}
\end{tabular} & $\begin{array}{l}\text { ঃ } \\
\stackrel{1}{-1} \\
\end{array}$ & 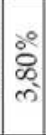 & 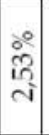 & & 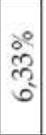 & 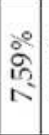 & 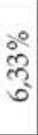 & $\begin{array}{l}20 \\
13 \\
10 \\
c 1\end{array}$ & @2 & 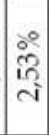 & 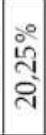 & $\begin{array}{l}\vdots \\
\dot{\infty} \\
\infty \\
\infty^{2}\end{array}$ & $\begin{array}{l}\circ \\
\vdots \\
\infty \\
\text { ஸे }\end{array}$ & $\begin{array}{l}\circ \\
\stackrel{0}{ } \\
\overbrace{}^{2}\end{array}$ & $\begin{array}{l}\because \\
\check{0} \\
\infty \\
\infty\end{array}$ & $\begin{array}{l}\stackrel{0}{2} \\
\overrightarrow{0} \\
\infty^{\circ}\end{array}$ & సิ & & $\begin{array}{c}0 \\
3 \\
0 \\
0 \\
0\end{array}$ & స̃ & \begin{tabular}{l|l}
0 \\
$\vdots$ \\
$\infty$ \\
$\infty$ \\
$\infty$ \\
$\infty$ \\
$\vdots$
\end{tabular} & $\begin{array}{l}\text { o̊ } \\
\text { în } \\
\text { î }\end{array}$ & & $\begin{array}{l}\text { 20 } \\
\text { î } \\
\text { तi }\end{array}$ & $\stackrel{\circ}{\circ}$ & R \\
\hline & $\gtrsim$ & & $\begin{array}{l}\text { 8े } \\
\text { ¿ें }\end{array}$ & $\begin{array}{l}i^{\circ} \\
\text { రై } \\
0\end{array}$ & & $\begin{array}{l}\stackrel{0}{0} \\
\text { ţ} \\
0\end{array}$ & $\begin{array}{l}\circ \\
\vdots \\
0 \\
0 \\
0\end{array}$ & $\begin{array}{l}\vdots 0 \\
\vdots \\
\vdots \\
0\end{array}$ & & 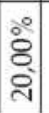 & & & ஃ̊ & & $\begin{array}{l}\vdots 0 \\
\vdots 0 \\
0 \\
0\end{array}$ & 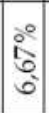 & & & & $\stackrel{\circ}{\stackrel{\circ}{ి}}$ & & & & & & & & & $\begin{array}{l}\circ \\
\stackrel{0}{0}\end{array}$ & $\stackrel{2}{2}$ \\
\hline & Z & $\begin{array}{l}\stackrel{\circ}{+} \\
\stackrel{+}{ \pm} \\
\vec{N}\end{array}$ & 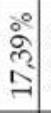 & $\begin{array}{l}\therefore 0 \\
\stackrel{1}{ } \\
\infty^{\circ}\end{array}$ & & & 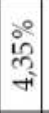 & & 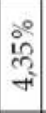 & $\begin{array}{l}\stackrel{0}{\circ} \\
0^{\circ} \\
\infty^{\circ}\end{array}$ & & & 总 & $\begin{array}{c}0 \\
13 \\
i 3 \\
+3\end{array}$ & & $\begin{array}{c}2 \\
13 \\
13 \\
+4 \\
-4\end{array}$ & & 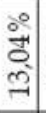 & 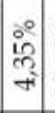 & $\begin{array}{l}20 \\
13 \\
12 \\
2\end{array}$ & & & & & & 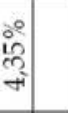 & & 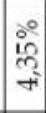 & ¿े & 2 \\
\hline & $\underset{q}{4}$ & & & & & & $\begin{array}{l}\text { ते } \\
\text { तี }\end{array}$ & & & $\begin{array}{l}\text { ปे } \\
\text { ปิ }\end{array}$ & & $\stackrel{\circ}{=}$ & & $\begin{array}{l}\stackrel{0}{=} \\
= \\
=\end{array}$ & & $\begin{array}{l}\stackrel{0}{=} \\
= \\
=\end{array}$ & & & $\begin{array}{l}\stackrel{2}{1} \\
\text { ปิ }\end{array}$ & $\stackrel{8}{\circ}$ & & & & & & & & & $\stackrel{\circ}{8}$ & $a$ \\
\hline 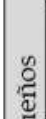 & 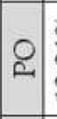 & 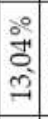 & 品 & & & & & & & 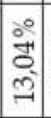 & $\begin{array}{l}\stackrel{\circ}{\circ} \\
\stackrel{\infty}{\circ}\end{array}$ & & 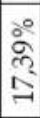 & $\begin{array}{c}\stackrel{0}{2} \\
\stackrel{1}{1} \\
\infty\end{array}$ & $\begin{array}{l}\stackrel{0}{0} \\
\stackrel{\rho}{1} \\
\infty\end{array}$ & & 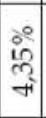 & $\begin{array}{l}\stackrel{0}{2} \\
\stackrel{1}{ } \\
\infty \\
\infty\end{array}$ & & 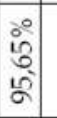 & & & & îำ & 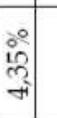 & & & & $\stackrel{\text { : }}{\stackrel{-}{-}}$ & 2 \\
\hline 䒕 & 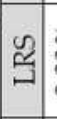 & $\begin{array}{l}\text { ㅇํㅇ } \\
3 \\
\infty\end{array}$ & $\begin{array}{l}20 \\
2 \\
\infty \\
\infty\end{array}$ & & & & & $\begin{array}{l}\stackrel{0}{\circ} \\
\vdots \\
0 \\
0\end{array}$ & 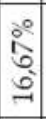 & & & & & & $\begin{array}{l}20 \\
3 \\
\infty \\
\infty \\
\infty\end{array}$ & & & & \begin{tabular}{l}
$\circ$ \\
\hdashline \\
0 \\
0 \\
-1
\end{tabular} & $\begin{array}{l}8 \\
8 \\
10 \\
10\end{array}$ & 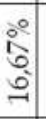 & & & & 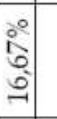 & & $\begin{array}{l}2 \\
3 \\
\infty \\
\infty\end{array}$ & $\begin{array}{l}20 \\
\text { की } \\
\infty\end{array}$ & 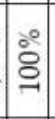 & $\cong$ \\
\hline & 몀 & 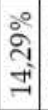 & 웅 & 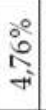 & 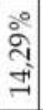 & & $\begin{array}{l}\text { 웅 } \\
\text { 옹 } \\
9\end{array}$ & & 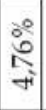 & & 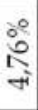 & & & $\begin{array}{l}\stackrel{0}{0} \\
\frac{1}{7} \\
7^{2}\end{array}$ & \begin{tabular}{l}
0 \\
0 \\
\multirow{2}{*}{} \\
fi
\end{tabular} & & & \begin{tabular}{l}
0 \\
\multirow{2}{*}{} \\
\multirow{+}{*}{}
\end{tabular} & $\left|\begin{array}{c}0 \\
0 \\
1 \\
+i \\
-i\end{array}\right|$ & $\stackrel{\circ}{\circ}$ & & & & & & & & & $\stackrel{\text { : }}{\stackrel{0}{8}}$ & $\vec{\lambda}$ \\
\hline & $\stackrel{\leftrightarrows}{\mapsto}$ & 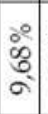 & 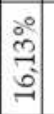 & & $\begin{array}{l}\stackrel{2}{2} \\
\text { సै} \\
m^{2}\end{array}$ & & 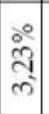 & 竎 & & 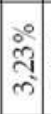 & $\begin{array}{l}\text { 方 } \\
\text { ?ै }\end{array}$ & & @ొ & $\begin{array}{l}\stackrel{2}{2} \\
\hat{2} \\
n^{2}\end{array}$ & $\begin{array}{l}\circ \\
\infty \\
10 \\
\text { तี }\end{array}$ & & & & & 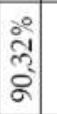 & & & & & & 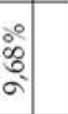 & & $\begin{array}{l}\circ \\
08 \\
8 \\
\sigma\end{array}$ & $\stackrel{0}{8}$ & $\overrightarrow{~ क े ~}$ \\
\hline & 좋 & $\begin{array}{l}\text { के } \\
\text { ڤె } \\
\text { ले }\end{array}$ & $\begin{array}{l}\circ \\
\infty \\
3 \\
\infty 3 \\
\infty\end{array}$ & & & & & & & & & & & & & & & & & $\stackrel{8}{8}$ & & & & & & & & & ஓి & $\infty$ \\
\hline & $\begin{array}{l}0 \\
0 \\
0 \\
0 \\
\overline{2} \\
0 \\
0 \\
0 \\
\text { : }\end{array}$ & 을 & 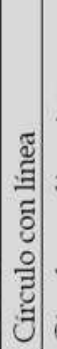 & 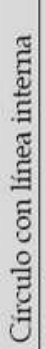 & 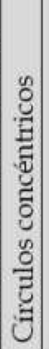 & 节 & 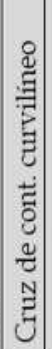 & 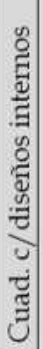 & 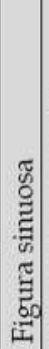 & 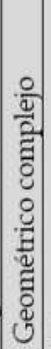 & 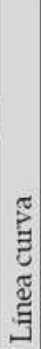 & 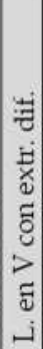 & 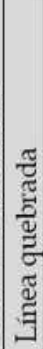 & 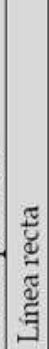 & 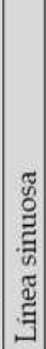 & 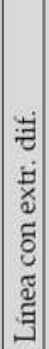 & 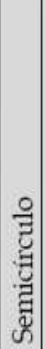 & 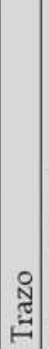 & 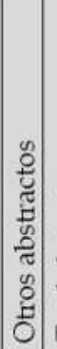 & 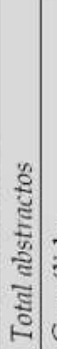 & 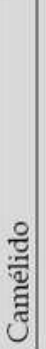 & : & 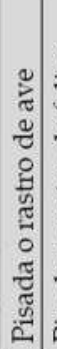 & 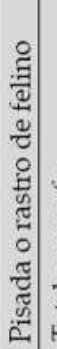 & 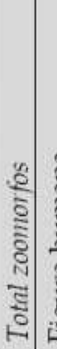 & 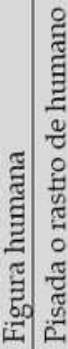 & 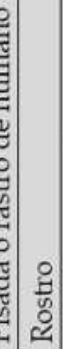 & 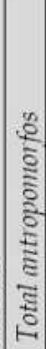 & 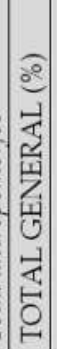 & 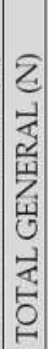 \\
\hline
\end{tabular}

Tabla 5. Tipos de motivos documentados en el norte de la sierra de Valle Fértil (no se consideran los indeterminados).

Referencias: Cuad. $=$ Cuadrilátero, $c=$ con, L. $=$ Linea, extr. dif. $=$ extremos diferenciados 


\begin{tabular}{|c|c|c|c|c|c|c|c|c|}
\hline \multirow{2}{*}{\multicolumn{2}{|c|}{ Tipc }} & \multicolumn{5}{|c|}{ Subtipos } & \multirow{2}{*}{$\begin{array}{c}\text { Total } \\
\%\end{array}$} & \multirow{2}{*}{$\begin{array}{c}\text { Total } \\
\mathrm{N}\end{array}$} \\
\hline & & A & B & $\mathrm{C}$ & D & $\mathrm{E}$ & & \\
\hline \multirow{12}{*}{ 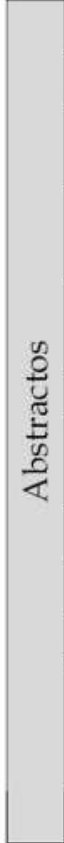 } & Círculo & $60,23 \%$ & $23,86 \%$ & $15,91 \%$ & & & $100 \%$ & 88 \\
\hline & Círculo con línea & $54,69 \%$ & $45,31 \%$ & & & & $100 \%$ & 64 \\
\hline & $\begin{array}{l}\text { Círculo con línea } \\
\text { interna }\end{array}$ & $73,33 \%$ & $26,67 \%$ & & & & $100 \%$ & 30 \\
\hline & $\begin{array}{l}\text { Círculos } \\
\text { Concéntricos }\end{array}$ & $68,75 \%$ & $31,25 \%$ & & & & $100 \%$ & 16 \\
\hline & $\begin{array}{l}\text { Cruz de contorno } \\
\text { curvilíneo }\end{array}$ & $54,29 \%$ & $20,00 \%$ & $25,71 \%$ & & & $100 \%$ & 35 \\
\hline & Figura sinuosa & $52,00 \%$ & $48,00 \%$ & & & & $100 \%$ & 25 \\
\hline & $\begin{array}{l}\text { Geométrico } \\
\text { complejo }\end{array}$ & $27,08 \%$ & $72,92 \%$ & & & & $100 \%$ & 48 \\
\hline & Línea curva & $76,67 \%$ & $23,33 \%$ & & & & $100 \%$ & 30 \\
\hline & Línea quebrada & $66,15 \%$ & $33,85 \%$ & & & & $100 \%$ & 65 \\
\hline & Línea sinuosa & $87,14 \%$ & $12,86 \%$ & & & & $100 \%$ & 70 \\
\hline & $\begin{array}{l}\text { Línea con } \\
\text { extremos } \\
\text { diferenciados }\end{array}$ & $25,00 \%$ & $11,11 \%$ & $22,22 \%$ & $27,78 \%$ & $13,89 \%$ & $100 \%$ & 36 \\
\hline & Semicírculo & $77,27 \%$ & $22,73 \%$ & & & & $100 \%$ & 22 \\
\hline
\end{tabular}

Tabla 6. Subtipos de motivos presentes en el área.

ejecución de los grabados. Éstas enmarcan un curso de agua temporario y, específicamente un lagar, reservorio natural de agua sobre lecho rocoso que puede perdurar entre uno a tres meses (Herrera y Damiani com. pers.). Los dos sitios grandes se ubican en emplazamientos de mayor altitud (entre 1350 y $1500 \mathrm{msnm}$ ) donde convergen varias quebradas (PQ) o, como en el caso de PPM, en un portezuelo o abra. Cabe destacar que tanto el sitio mediano como los grandes se localizarían en el cordón montañoso dado que su altitud supera los $1300 \mathrm{msnm}$.

Resulta de interés evaluar la representación de los distintos tipos de motivos y subtipos en cada uno de los sitios. En primer lugar, se evidencia una serie de similitudes entre ellos, siendo la más notoria el predominio de motivos abstractos en todos ellos en una frecuencia mayor al 80\%, a excepción del caso de LRS (Tablas 4 y 5). Mientras que prácticamente todos los tipos se registran en sitios medianos y grandes, se observa que algunos se encuentran escasamente representados en los pequeños. Así, ciertos tipos se registran de manera casi exclusiva en los grandes y el mediano (círculos con líneas internas, círculos concéntricos, cruces, cuadriláteros con diseños internos, figuras sinuosas, líneas curvas, líneas en $\mathrm{V}$ con extremos diferenciados, líneas con extremos diferenciados, semicírculos y trazos).

Por otra parte, los zoomorfos se presentan en mayores porcentajes en el sitio mediano $(8,24 \%)$ y los grandes $(8,63 \%)$ en contraposición con los pequeños $(1,97 \%)$ (Tabla 4$)$. En particular, se documentan en cinco de los 11 sitios, en los dos sitios grandes, en el mediano y sólo en dos de los pequeños. Si se consideran los tipos de motivos (Tabla 5), se observan frecuencias variables de cada uno de ellos. Los cuatro tipos se documentan en conjunto solamente en el sitio grande PQ, mientras que en los sitios pequeños hay dos camélidos en 
LRS y una pisada de felino en PO. Así, los tridígitos se observan de manera exclusiva en los sitios medianos y grandes y las lagartijas únicamente en $P Q$.

Por último, los motivos antropomorfos se registran en proporciones mayores en los sitios pequeños $(3,29 \%)$ seguidos por el mediano $(2,35 \%)$ y los grandes en último lugar $(0,98 \%)$ (Tabla 4). Específicamente, se localizan en cinco sitios, en este caso, en tres de los pequeños, en el mediano y en uno de los grandes, destacando su ausencia en PPM. Al considerarse los tipos (Tabla 5), mientras que las figuras humanas se encuentran en bajas densidades en sitios de diversas dimensiones, las huellas sólo se hallan en PQ y los rostros uno en PQ y otro en LRS.

En términos generales, se observa que a medida que se incrementa la frecuencia de motivos, aumenta la cantidad de tipos identificados en cada sitio. Sin embargo, destaca la representación casi exclusiva de determinados tipos de motivos en los sitios de dimensiones más grandes (por ejemplo, círculos concéntricos, figuras sinuosas, líneas con extremos diferenciados, lagartijas, tridígitos y huellas humanas) en contraposición con una distribución más homogénea de otros (círculos, círculos con línea, líneas quebradas y figuras humanas, entre otros). Al considerar los subtipos mencionados en el apartado anterior, se evidencia que toda la diversidad se registra únicamente en el sitio PQ. En particular, se destaca que los distintos subtipos de las cruces de contorno curvilíneo y de líneas con extremos diferenciados se encuentran en conjunto solamente en los sitios grandes y, en el primer caso, específicamente en $\mathrm{PQ}$, único sitio donde se documentaron las cruces dobles (subtipo B).

Por último, revisando la distribución de las superposiciones, se observó que en su mayoría (N: 15) se documentan en los sitios grandes, destacándose PQ con 11 de ellas. No obstante, resulta interesante destacar que los sitios pequeños presentan un índice mayor de superposiciones por cantidad de motivos.

\section{Comparación intra-sitio}

Por otra parte, también interesa evaluar la distribución de los motivos al interior de los sitios, así como el uso de los soportes. Como se mencionó anteriormente, en su mayor parte se seleccionaron bloques, ejecutándose grabados en una única cara o hasta en cinco de ellas. Sólo en uno de los sitios (QLL) se utilizaron paredes. A pesar de la amplia disponibilidad de soportes, el número utilizado en cada uno de los sitios es muy variable (Tabla 1). En los sitios pequeños se emplearon pocos bloques (entre 2 y 6 ), en el mediano 14 y en los grandes: 42 en PPM y 71 en PQ.

Los soportes empleados se distribuyen de manera diferencial, localizándose tanto ejemplos dispersos como concentrados, es decir, dos o más soportes ubicados a una distancia igual o menor a $5 \mathrm{~m}$ (Tabla 7). Así, se observa que los soportes con grabados tienden a estar concentrados. En los sitios pequeños generalmente se presenta una única concentración de dimensiones menores (entre 2 y 6 bloques), siendo las excepciones LT, constituido por dos concentraciones chicas de bloques, y PQC, conformado por dos bloques dispersos, es decir, ubicados a una distancia mayor a $5 \mathrm{~m}$. En el sitio mediano, que se compone de 14 paredes, mientras cinco soportes se encuentran en forma dispersa, los restantes se disponen en forma agrupada formando dos concentraciones de menores dimensiones, una de ellas de tres y la otra de seis paredes. En esta última, los soportes se ubican alrededor del lagar. 


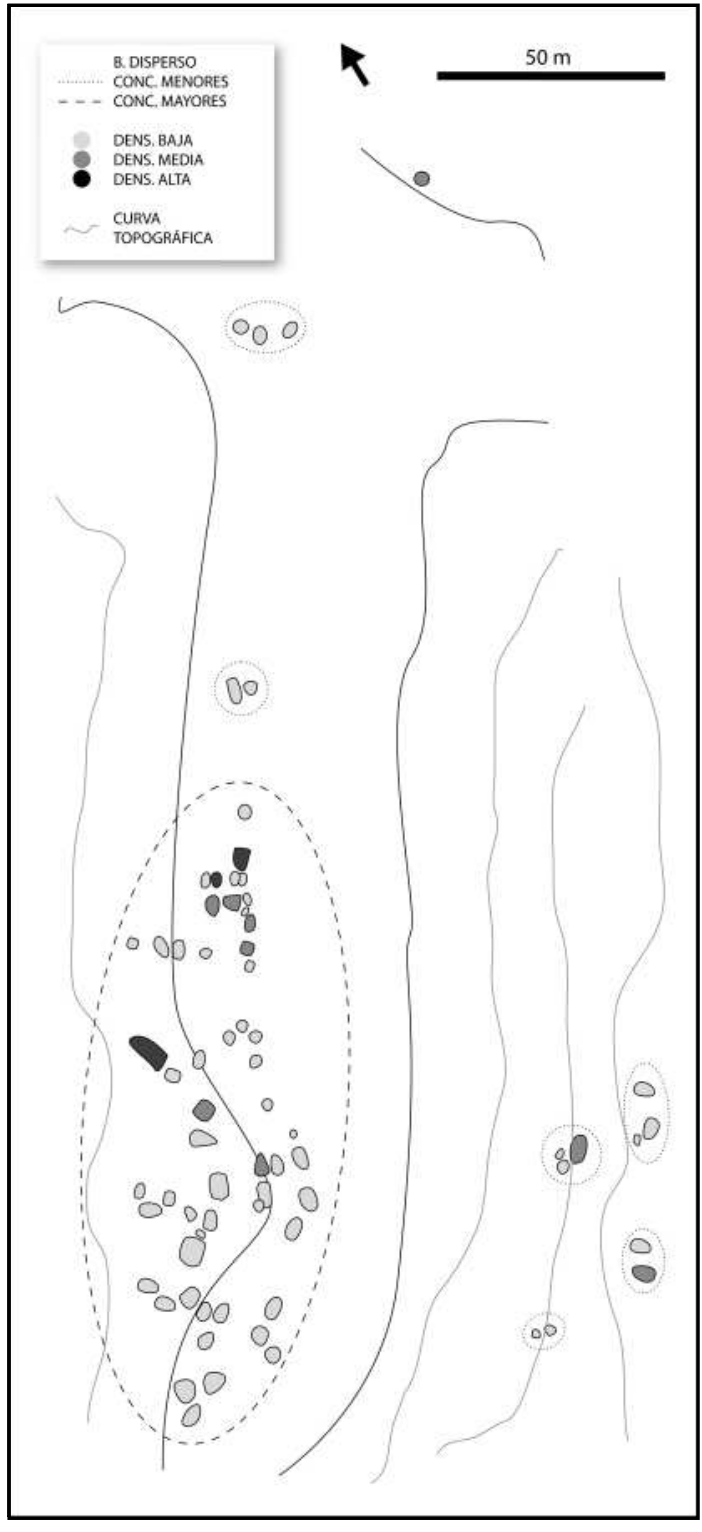

Figura 6. Croquis con la distribución de los bloques con grabados en el sitio $P Q$. Referencias: Conc. $=$ Concentración, Dens. $=$ Densidad.
En los sitios grandes también se relevaron soportes tanto dispersos como agrupados. No obstante, se destaca que en ellos se registran concentraciones de diversos tamaños, es decir, reuniendo diferente cantidad de bloques. Así, en ambos sitios hay seis concentraciones de dimensiones chicas (de 2 a 4 bloques) y una concentración mayor (Figura 6 y Tabla 7). En el caso de PPM esta última cuenta con 21 bloques y en PQ con 55. Los soportes restantes, un bloque en PQ y cuatro bloques en PPM se encuentran dispersos.

Por otra parte, se evidencia que los motivos fueron ejecutados en los distintos soportes en forma heterogénea. Así, se registran bloques de baja densidad de motivos ( 1 a 5 ), media (6 a 20) y alta (21 a 42) (Tabla 7 y Figura 6). En la mayor cantidad de soportes (N: 122) se ejecutaron de 1 a 5 motivos, presentando por tanto una densidad baja, sin importar las dimensiones de los sitios. No obstante, asimismo en todos los sitios se registraron en menor frecuencia soportes de densidades medias (entre 6 y 20 motivos). Destacan los casos de LRS, donde dos de los tres bloques presentan estas densidades, y QLL, en el cual casi la mitad de las paredes presentan esta cantidad de motivos. Solamente se registraron tres bloques de densidad alta (entre 21 y 42 motivos), todos ellos localizados en el sitio de mayores dimensiones (PQ).

Cuando se considera en conjunto la ubicación de los soportes y la cantidad de motivos ejecutados (Tabla 7), se observa que los soportes de densidades bajas y medias pueden presentarse tanto de manera dispersa como en concentraciones de distintas dimensiones. Encontraposición,losbloquesconuna altadensidad demotivosseubicanexclusivamenteen la concentración mayor del sitio PQ.

Resulta asimismo de interés considerar algunas particularidades referidas a la distribución de las distintas categorías y tipos de motivos al interior de los sitios ya que se evidencia que algunas de ellas se distribuyen de manera diferencial en los soportes. Ciertos tipos suelen presentarse en las concentraciones menores de distinto tamaño de sitio, siendo el caso de los círculos concéntricos (subtipo A), las cruces de contorno curvilíneo (subtipos B y C), los 
cuadriláteros con diseños internos y las líneas rectas y sinuosas (subtipo A). Dentro de los figurativos, se observa una situación semejante en las figuras humanas y los rostros. Por otra parte, algunos motivos se localizan en porcentajes más altos en las concentraciones de mayores dimensiones de los sitios grandes. Estos son: los círculos con líneas internas, las cruces, los semicírculos, las líneas con extremos diferenciados, los tridígitos, las lagartijas y las pisadas humanas. Resumiendo, se observa que algunos tipos de motivos presentan una distribución diferencial al interior de los sitios, de manera que se habrían seleccionado soportes de diversas características para su ejecución.

Finalmente, las superposiciones se registran casi exclusivamente en bloques que forman concentraciones, tanto pequeñas como grandes, y de densidades media y alta de motivos. Excepcionalmente se registró una superposición en un bloque disperso en el sitio PQ y dos casos de superposiciones en un bloque de baja densidad en el sitio PPM.

\section{Evidencias asociadas}

En este acápite se refiere brevemente las otras evidencias arqueológicas asociadas a los sitios con arte rupestre. Una primera apreciación fue realizada por Re y colaboradores (2009), buscándose aquí actualizar la información que se encuentra disponible. En primer lugar, en la Tabla 1 se evidencia que mientras que algunos sitios presentan diversas líneas de evidencia en conjunto, en otros el arte rupestre se encuentra de manera aislada.

\begin{tabular}{|c|c|c|c|c|c|c|c|c|c|}
\hline \multirow{2}{*}{\multicolumn{2}{|c|}{ Sitios }} & \multicolumn{2}{|c|}{$\begin{array}{c}\mathrm{S} . \\
\text { Dispersos }\end{array}$} & \multicolumn{2}{|c|}{$\begin{array}{l}\text { S. en Conc. } \\
\text { Menores }\end{array}$} & \multicolumn{3}{|c|}{$\begin{array}{l}\text { S. en Conc. } \\
\text { Mayores }\end{array}$} & \multirow{2}{*}{ Total } \\
\hline & & $\begin{array}{c}\text { Dens. } \\
\text { Baja }\end{array}$ & $\begin{array}{l}\text { Dens. } \\
\text { Media }\end{array}$ & $\begin{array}{c}\text { Dens. } \\
\text { Baja }\end{array}$ & $\begin{array}{l}\text { Dens. } \\
\text { Media }\end{array}$ & $\begin{array}{c}\text { Dens. } \\
\text { Baja }\end{array}$ & $\begin{array}{l}\text { Dens. } \\
\text { Media }\end{array}$ & $\begin{array}{l}\text { Dens. } \\
\text { Alta }\end{array}$ & \\
\hline \multirow{8}{*}{ Peq. } & \multirow{8}{*}{$\begin{array}{l}\text { Corral } \\
\text { LT } \\
\text { LRN } \\
\text { LRS } \\
\text { PO } \\
\text { PQC } \\
\text { QCCN } \\
\text { QV }\end{array}$} & & & 2 & & & & & 2 \\
\hline & & & & 4 & 2 & & & & 6 \\
\hline & & & & 3 & 1 & & & & 4 \\
\hline & & & & 1 & 2 & & & & 3 \\
\hline & & & & 4 & 1 & & & & 5 \\
\hline & & 1 & 1 & & & & & & 2 \\
\hline & & & & 6 & 1 & & & & 7 \\
\hline & & & & 2 & 1 & & & & 3 \\
\hline Med. & QLL & 3 & 2 & 4 & 4 & & & & 13 \\
\hline \multirow{2}{*}{$\begin{array}{l}\text { Gran } \\
\text { des }\end{array}$} & \multirow{3}{*}{$\begin{array}{l}\text { PPM } \\
\text { PQ }\end{array}$} & 4 & & 14 & 3 & 15 & 6 & & 42 \\
\hline & & & 1 & 13 & 2 & 46 & 6 & 3 & 71 \\
\hline Total & & 8 & 4 & 53 & 17 & 61 & 12 & 3 & 158 \\
\hline
\end{tabular}

Tabla 7. Clasificación de los soportes empleados de acuerdo a su ubicación (disperso, en concentración menor o en concentración mayor) y a la cantidad de motivos ejecutados (densidad baja, media o alta). Referencias: $S .=$ Soportes, Conc. $=$ Concentraciones, Dens. $=$ Densidad, 
De esta manera, se observa que la mitad de los sitios pequeños, ubicados en la faja pedemontana, se asocian directamente a concentraciones de material lítico y cerámico, bloques con morteros y/o estructuras circulares de piedra, algunas de colores (Tabla 1). Cabe aclarar que, si bien en QCCN y Corral no se registraron otras evidencias, éstos conforman con PQC una localidad arqueológica, encontrándose por tanto muy próximos (Figura 2). Éste también es el caso de LRS y LRN, los cuales se hallan a $500 \mathrm{~m}$ del sitio Los Rincones Estructuras, hallándose por tanto en relación a una serie de estructuras y material lítico y cerámico en superficie. Además, se debe tener presente que, en función de su cercanía a los poblados actuales y a la ruta provincial, algunos de los sitios pequeños estuvieron expuestos al huaqueo. Como se mencionó en el apartado Antecedentes, el análisis del material cerámico y lítico en PQC y LT, en conjunción con los fechados, permitió sugerir la realización actividades múltiples orientadas al procesamiento de recursos locales al menos durante el Período Agroalfarero Medio (Guráieb et al. 2010).

Como se mencionó antes, los sitios de mayores dimensiones se localizan en el cordón montañoso. El único sitio mediano identificado (QLL) se ubica en el extremo norte de la región estudiada y no se encuentra asociado a otro tipo de evidencias arqueológicas (Figura 2). Los dos sitios grandes, localizados en espacios de mayor altura, presentan diferentes características. Por un lado se registraron pequeñas cantidades de material lítico y cerámico en PPM, el cual se halla a $1350 \mathrm{msnm}$ en un portezuelo. En este último caso se debe tener presente su cercanía (500 m) a un conjunto de dos estructuras de piedra con gran cantidad de materiales y dos morteros asociados en la margen del río El Durazno (Rolandi et al. 2003) (Figura 2). Por otra parte, en PQ, ubicado a $1500 \mathrm{msnm}$ y en la confluencia de diversas quebradas, no se encontraron otros materiales arqueológicos asociados.

Cabe destacar que en el piedemonte del norte de la sierra de Valle Fértil se documentaron además otros sitios arqueológicos entre cuyas evidencias no se incluye el arte rupestre (Guráieb et al. 2007; Re et al. 2009; Rolandi et al. 2003). En éstos se registraron diversas estructuras de piedra, concentraciones de material lítico y cerámico en superficie y, en algunos casos, morteros. Estos son, de norte a sur, Los Pasantes, Loma Las Vizcachas, Piedras de Afilar, Estructura Río de los Mineros, Loma del Balde Viejo, Río El Durazno, Los Rincones Estructuras y Morteritos (Figura 2).

De tal manera, las restantes líneas de evidencia arqueológicas apuntan a la realización de diverso tipo de actividades en la faja pedemontana de la sierra de Valle Fértil, principalmente en los ambientes de tipo rincón y en asociación a los cauces temporarios de los ríos de la región. Por el contrario, la ocupación humana del cordón montañoso se halla señalizada principalmente por el arte rupestre.

\section{Discusión y conclusiones}

Tal como se anticipara en la introducción, los objetivos del presente artículo son, por un lado, la profundización del estudio del arte rupestre del norte de la sierra de Valle Fértil y, por el otro, la evaluación de los diversos roles adoptados por el mismo en las sociedades del pasado. A lo largo de las páginas se hizo evidente, a partir del análisis de los motivos registrados, tanto semejanzas como diferencias al interior del área seleccionada. Así, se observó que el arte rupestre de la misma se caracteriza por un claro predominio de grabados abstractos. Dentro de los mismos se identificó una alta diversidad morfológica, diferenciándose 22 tipos y varios subtipos al interior de más de la mitad de ellos. Se observó 
una mayor frecuencia de círculos, líneas sinuosas, líneas quebradas y círculos con línea. Por otra parte, los motivos figurativos, tanto zoomorfos (4 tipos) como antropomorfos (3 tipos), se encontraron más escasamente representados. En términos generales, las representaciones fueron ejecutadas en bloques de granito concentrados, es decir, dos o más soportes ubicados a una distancia igual o menor a $5 \mathrm{~m}$. Se observó que la mayor parte de los soportes presentan una baja densidad de motivos (1 a 5).

No obstante, también quedó claro que los motivos, así como algunos tipos en particular, se distribuían de manera diferencial en el espacio. Así, se distinguieron ocho sitios pequeños (1 a 50 motivos), uno mediano (51 a 150 motivos) y dos grandes (más de 151 motivos). Como se planteó antes, los sitios pequeños son los más comunes y se encuentran en el piedemonte de la sierra, generalmente en ambientes de rincón y en cercanía a cursos de agua temporarios. De esta manera, desde los mismos se suele tener una visión del entorno muy restringida. Asimismo, se destacó su asociación con evidencias de ocupación relativamente estable asignables al período Agroalfarero Medio, si bien se reconoció a su vez un posible lapso temporal más amplio (Guráieb et al. 2010). Se encuentran en la zona más intensamente ocupada actualmente y de mayor potencial productivo. En todos ellos se registraron frecuencias bajas de motivos, desde 3 casos en el sitio Corral hasta 34 en LT. Éstos se disponen generalmente en una única concentración de 2 a 6 bloques, los cuales presentan en su mayoría una baja densidad de motivos. Se registra una menor variedad de motivos rupestres, con escasos figurativos, si bien destaca el porcentaje levemente mayor de la categoría antropomorfos $(3,29 \%)$.

Dentro de los sitios pequeños se observaron asimismo algunas particularidades. Por ejemplo, llama la atención el sitio LRS, el cual presenta una mayor frecuencia de figurativos, incluyendo tanto camélidos como un rostro, y donde dos de los tres bloques que lo componen son de densidad media (6 a 20 motivos). Por otra parte, LT es el que cuenta con una mayor cantidad relativa de motivos y bloques empleados, encontrándose dispuestos los mismos en dos concentraciones pequeñas que enmarcan el sector con materiales líticos y cerámicos. Por último y, como se mencionó anteriormente, tanto $\mathrm{PO}$ como QV presentan condiciones ambientales diferenciales a las del resto de los sitios pequeños considerados.

Por otra parte, los sitios con una mayor cantidad de motivos (el mediano y los grandes) se encuentran a una mayor altitud, localizándose por tanto en el cordón montañoso, si bien en distintos sectores del mismo. En los mismos se registró la presencia casi exclusiva de determinados tipos de motivos como los círculos concéntricos, las figuras sinuosas y las líneas con extremos diferenciados, entre los abstractos y de los tridígitos, dentro de los zoomorfos.

El único sitio mediano detectado, QLL con 85 motivos, resalta por su ubicación en el extremo norte del área seleccionada en este artículo, siendo el más alejado, y por su asociación con un lagar, el cual actúa como reservorio temporal de agua en determinadas estaciones. Destaca la ausencia de otras evidencias arqueológicas en proximidad a los grabados. Este sitio es el único donde se utilizaron paredes para ejecutar las representaciones rupestres, distribuyéndose en dos concentraciones pequeñas y algunos soportes dispersos. Casi la mitad de las mismas presentan una densidad media de motivos. Llama la atención una alta representación relativa de los zoomorfos $(8,24 \%)$ y en menor medida de los antropomorfos $(2,35 \%)$. 
Por otra parte, los sitios grandes, localizados a mayor altitud, se caracterizan precisamente por una mayor cantidad de motivos distribuidos tanto en bloques dispersos como en concentraciones de diversas dimensiones. Asimismo, concentran la mayor cantidad de superposiciones de la zona de valles y quebradas. Es de interés destacar una alta frecuencia relativa de zoomorfos $(8,63 \%)$ y en contraposición una muy escasa representación de antropomorfos (0,98\%). En particular, PPM cuenta 198 motivos distribuidos en 42 bloques. Si bien presenta una gran variedad de motivos, destaca la ausencia de antropomorfos en cualquiera de sus variantes. Como se mencionó antes, el sitio se localiza en un portezuelo con amplia visibilidad en dos direcciones, a 500 m de evidencias de ocupación en las márgenes del río El Durazno.

Por último, PQ es el sitio de mayores dimensiones del área considerada con 312 motivos en 71 bloques. Se destaca por ser el único que presenta toda la variedad de tipos y subtipos de motivos definidos en este trabajo. De esta manera, algunos de ellos son exclusivos de este sitio, como las cruces de contorno curvilíneo (subtipo B), las pisadas humanas y las lagartijas. Además, sólo en él se han documentado bloques con una alta densidad de motivos (21 a 42 motivos) y 11 casos de superposiciones. En contraposición, llama la atención su mayor altitud y la ausencia de otras evidencias arqueológicas de ocupación humana.

La necesidad de considerar el arte rupestre en su contexto, evaluando tanto las restantes líneas de evidencias como su emplazamiento particular ha sido reconocida por numerosos autores de diversos marcos teóricos (Aschero 1988; Conkey 2001; Hartley y Wolley Vawser 1998; Mithen 1996; Quinlan y Woody 2003; Schaafsma 1985; entre otros). Se ha planteado que los distintos contextos del arte rupestre inciden en los roles que el mismo habría cumplido, ya que éstos indicarían con quién o quienes se quería comunicar e interactuar a través de él. De esta manera, Quinlan y Woody (2003) proponen que el arte rupestre ubicado en o en proximidad a lugares de habitación, es decir, en un contexto doméstico, habría sido encontrado por gran parte de la sociedad en sus actividades cotidianas. Aquel emplazado en lugares más alejados solamente habría sido ejecutado y/o utilizado por un segmento de la población. Estos autores sostienen que las representaciones ubicadas en contextos domésticos habrían sido potencialmente utilizadas para negociar relaciones sociales y definir identidades culturales. Por otra parte, Hartley y Wolley Vawser (1998) sostienen que el arte rupestre podría haber sido utilizado como demarcador de caminos a fin de facilitar la orientación espacial de las personas en el tránsito por el paisaje (ver Podestá et al. 2011 para una aplicación de estos conceptos al arte rupestre histórico de Ischigualasto) o también para restringir el acceso a determinados lugares mediante una reclamación de propiedad. Estos autores representan sólo algunos ejemplos de los roles que se le ha asignado al arte rupestre.

A falta de dataciones directas, la asociación entre el arte rupestre y las restantes evidencias es un problema que requiere de evaluación caso a caso. En el área de investigación, las escasas superposiciones y la ausencia de diferenciación en las pátinas de los grabados ha sustentado la consideración de un lapso temporal de ejecución relativamente corto, entre ca. 600 y 1500 años d.C. sobre la base de distintos indicadores (Re et al. 2009). Asimismo, las semejanzas observadas en los tipos de motivos en un área relativamente pequeña (Figura 2), es decir, la presencia de un mismo repertorio de motivos, permiten asumir que las diferentes localizaciones del arte rupestre analizado en este trabajo eran conocidas y/o utilizadas por los mismos grupos humanos. De esta manera, se asume en un principio que los productores del arte rupestre habrían sido parte de los mismos grupos cuyas actividades son atestiguadas por las restantes evidencias arqueológicas. 
Así, se plantea que el contexto de ejecución del arte rupestre en el área considerada ha sido variado. En primera instancia, se sostiene que los motivos localizados en sitios pequeños habrían sido ejecutados y/o utilizados en su mayoría en lugares de habitación más o menos prolongada y, por tanto, en un contexto doméstico, siendo partícipes todos los integrantes de la sociedad. En contraposición, aquellos ubicados en el sitio mediano y los grandes se relacionarían principalmente con espacios de tránsito y localización de recursos particulares, cumpliendo un rol en tanto demarcadores espaciales para la circulación. No obstante, estos sitios presentan particularidades. Mientras que PPM se encuentra próximo a evidencias de ocupación permanente, éste no es el caso de QLL y PQ. Así, cabe preguntarse en qué medida estos últimos fueron producidos y/o utilizados por la sociedad en su conjunto o solamente por un segmento de ella.

En este punto, es de interés retomar una distinción realizada por Nielsen (2006). Este autor resalta la necesidad de evaluar en los estudios de interacción tanto los nodos como los internodos, aquellos espacios "vacíos" o escasamente poblados que están en el medio, cuya ocupación se caracteriza por ser de tránsito o con objeto de tareas extractivas. Plantea que el registro arqueológico de estos últimos espacios tiende a ser poco denso y, por lo tanto, poco visible y obstrusivo, a menos que se dé una importante redundancia en su uso. Se debe tener presente que el investigador plantea que la definición de los mismos dependerá de la escala de análisis. A continuación se evalúa esta problemática en el caso bajo estudio en diferentes escalas espaciales. En primer lugar, se la considera al interior de la zona de valles y quebradas, área seleccionada en este artículo. Luego esta última es contemplada en conjunto con la colindante hoyada de Ischigualasto, la cual también es parte del área de investigación tal como se mencionara en apartados precedentes. Por último, se plantea una primera comparación en una escala espacial más amplia con regiones más alejadas y abordadas por otros investigadores.

$\mathrm{Al}$ interior de la zona de valles y quebradas, es posible sugerir que la faja pedemontana, la cual presenta la mayor cantidad de sitios con y sin grabados, habría funcionado como un nodo de las ocupaciones agroalfareras prehispánicas, es decir, donde se habrían encontrado los asentamientos relativamente permanentes. Al mismo tiempo, otros espacios como el cordón montañoso habrían cumplido un rol internodal. En este sentido, lugares como PPM, PQ y QLL habrían sido espacios de tránsito u objeto de tareas extractivas. Así, se destaca que los espacios internodales en el área considerada habrían sido demarcados mediante una mayor cantidad y diversidad de motivos rupestres.

Si se considera la hoyada de Ischigualasto, se evidencia una menor cantidad de motivos y diversidad de abstractos en conjunto con una mayor frecuencia relativa y variedad de motivos figurativos (Re et al. 2009; Romero y Re 2011). Este hecho resulta de interés dado que se ha planteado que esta hoyada habría sido un espacio internodal en función de sus características ambientales en tiempos prehispánicos (Romero y Re 2011) y aún en momentos históricos (Podestá et al. 2011). Siendo así, a futuro deberá evaluarse la posibilidad de que distintos espacios de tránsito hayan sido demarcados de diferentes maneras.

Si se cambia la escala y se considera una perspectiva espacial más amplia, se debe reconsiderar los espacios que habrían actuado como nodos e internodos de la interacción. Según Nielsen (2006), en este caso en los nodos se observarían densidades altas de población estable mientras que en los internodos se registrarían densidades relativamente bajas o nulas de población. Como se describió en los antecedentes, las investigaciones en la provincia 
de San Juan se han focalizado en los valles preandinos y precordilleranos, destacándose la diversidad y cantidad de evidencias arqueológicas que apuntan a ocupaciones intensas durante un amplio lapso temporal (Gambier 2000; García 2010). Por otra parte, en el área de investigación el análisis del registro arqueológico de dos de los sitios con mayor cantidad de evidencias de la faja pedemontana (PQC y LT) apunta a ocupaciones poco densas enfocadas en el procesamiento de recursos locales (Guráieb et al. 2010). De esta manera, en primera instancia, en una escala espacial amplia, podría considerarse al área de estudio, que incluye tanto la hoyada de Ischigualasto como las estribaciones septentrionales de la sierra de Valle Fértil, como un espacio internodal, ya que probablemente presentaría una baja densidad relativa de población. No obstante, dado que las investigaciones se iniciaron en tiempos recientes, se espera que las nuevas evidencias que se generen a futuro permitan evaluar de mejor manera esta idea .

A fin de considerar la interacción en una escala espacial amplia, cabe reflexionar sobre las similitudes y diferencias observadas con el arte rupestre de regiones cercanas. Si bien la comparación muchas veces se dificulta por la ausencia de datos cuantitativos, se evidencia que hacia el norte del área de estudio en el sur de la provincia de La Rioja en el Parque Nacional Talampaya (Ferraro 2005; Giordano y Gonaldi 1991), en Los Colorados (Falchi y Torres 2010; INAPL 2009) y en Palancho (Falchi et al. en este volumen) se registra una mayor frecuencia relativa y diversidad de motivos figurativos, así como un rango más amplio de técnicas de grabado. Mientras que se comparten algunos motivos abstractos como las líneas rectas, sinuosas y quebradas, círculos y círculos con línea, cruces de contorno curvilíneo y líneas con extremos diferenciados y figurativos como camélidos, figuras y huellas humanas, pisadas de felino y tridígitos, éstos se encuentran en diferentes porcentajes. Además, algunos tipos y diseños son exclusivos de determinadas áreas. Así, en el norte de la sierra de Valle Fértil se encuentran ausentes las líneas y figuras escalonadas y almenadas, los enmarcados, los suris y huellas de camélidos. Por otra parte, cuando se compara con el arte rupestre registrado al sur de la sierra de Valle Fértil y norte de La Huerta, se observan similitudes relacionadas con el emplazamiento de los sitios y los tipos de motivos registrados (figuras humanas, tridígitos, camélido, distintas variedades de líneas y círculos y cuadrilátero con diseños internos) (Cahiza 2006-2007). No se habrían registrado casos de cruces de contorno curvilíneo, líneas con extremos diferenciados, rostros, pisadas humanas, lagartijas y huellas de felino, si bien cabe tener presente las posibles diferencias de criterio entre los investigadores. A pesar de que no se encuentran disponibles datos cuantitativos, los sitios referidos parecen ser pequeños y medianos en términos de cantidad de motivos y soportes utilizados para su ejecución.

La comparación con las representaciones rupestres de otras regiones de San Juan como los valles preandinos y precordilleranos en esta instancia es aún más difícil. No obstante, se evidenciaría en los mismos una mayor cantidad de grabados y una mayor diversidad morfológica, incluyendo gran variedad de diseños de motivos figurativos (García et al. 2011; López y García 2011; Riveros 2010, 2011). Es de esperar que a medida que avancen las investigaciones se pueda explorar esta vía de la comparación.

Dado los escasos datos cronológicos disponibles en las distintas áreas, todavía resulta difícil establecer hasta qué punto las diferencias entre ellas se relacionan con distintos momentos de ejecución, tal como se observara en Palancho (Falchi et al. en este volumen) o diversas esferas de interacción social, en las cuales el arte rupestre podría haber actuado como un demarcador de tipo social. Se espera que las futuras investigaciones puedan avanzar en este sentido. 
Concluyendo, el estudio del arte rupestre del norte de la sierra de Valle Fértil ha permitido establecer que los roles adoptados por el mismo son diversos y de ninguna manera simples de establecer. Si bien se entiende que todas las representaciones rupestres pueden ser entendidas como una forma de comunicación, el contenido de la información transmitida así como el segmento de la sociedad con el que se desea comunicar e interactuar es variable, destacándose la necesidad de llevar a cabo un análisis contextual. Por otra parte, se espera que los datos aportados e interrogantes planteados demuestren que las investigaciones arqueológicas en el noreste de la provincia de San Juan se encuentran en su inicio y que su abordaje y profundización a futuro serán de gran interés y utilidad asimismo para comprender las ocupaciones humanas en un área de transición entre el Noroeste y el Centro-Oeste argentino.

Agradecimientos

Queremos agradecer a todos los integrantes del equipo que colaboraron en diferentes instancias de este trabajo, especialmente a Diana Rolandi y María Pía Falchi quienes nos acompañaron en todos los relevamientos. También a los pobladores de Baldecitos, Los Rincones y Balde del Rosario quienes hicieron posible los trabajos de campo, en particular a Dante Herrera y Miguel Ontivero. A Matías Salinas por colaborar con el tratamiento digital de las figuras. Al evaluador anónimo y a Pablo Cahiza por sus valiosos comentarios. Finalmente a los editores de Comechingonia por la oportunidad de publicar este trabajo.

\section{Bibliografía citada}

Ardissone, R. y M. Grondona

1953 La instalación aborigen en Valle Fértil. Facultad de Filosofía y Letras, Universidad de Buenos Aires, Buenos Aires.

Aschero, C. A.

1988 Pinturas rupestres, actividades y recursos naturales: un encuadre arqueológico. Arqueología Contemporánea Argentina. Actualidad y Perspectivas (ed. por H. Yacobaccio), pp. 109-145. Ediciones Búsqueda, Buenos Aires.

Cahiza, P.

2006-2007 Una perspectiva espacial para el estudio de la representaciones rupestres de Valle Fértil (provincia de San Juan). Cuadernos del INAPL 21: 253-258.

2007 Las sociedades formativas tardías de Valle Fértil, San Juan. Comechingonia. Revista de Arqueología 10: 79-94.

Conkey, M.

2001 Hunting for images, gathering up meanings: art for life in hunting-gathering societies. Hunter-gatherers. An interdisciplinary perspective (ed. por C. Panter-Brick, R. Layton y P. Rowley-Conwy), pp. 267-291. Cambridge University Press, Cambridge.

Consens, $\mathrm{M}$.

2003 San Juan y su arte rupestre: acotaciones críticas a intentos de sistematización. Actas del XIII Congreso Nacional de Arqueología Argentina, Tomo 3, pp. 185-200. Córdoba.

Falchi, M. P. y M. Torres

2010 Recursos didácticos para la valoración y conservación de sitios arqueológicos con arte rupestre. Articulo 81, Anais do Congresso Internacional de Arte rupestre IFRAO. Fundhamentos IX vol. 4, pp. 1101-1109. Fundação Museu do Homen Americano. Piauí, Brasil. 
Ferraro, L.

2005 Los Pizarrones: investigación, conservación y difusión de arte rupestre en el Parque Nacional Talampaya. Tesis de Licenciatura. Carrera de Ciencias Antropológicas. Facultad de Filosofía y Letras, Universidad de Buenos Aires, Buenos Aires.

Gambier, M.

2000 Prehistoria de San Juan. Ansilta Editora, San Juan.

García, A.

2010 Arqueología prehistórica de San Juan. La conquista indígena de los dominios del cóndor y el guanaco. Universidad Nacional de San Juan, San Juan.

García, A., C. López y O. Damiani

2011 Relevamiento de sitios con representaciones rupestres en el valle de Calingasta (San Juan). Ponencia presentada a las IX Jornadas de Investigadores en Arqueología y Etnohistoria del Centro-Oeste del País. 24 al 26 de Agosto de 2011. Río Cuarto, Universidad Nacional de Río Cuarto.

García Llorca, J., P. A. Cahiza y J. P. Aguilar

2010 Análisis zooarqueológico de los componentes formativos del alero Las Tumanas, Valle Fértil. Informe preliminar. Arqueología Argentina en el Bicentenario de la Revolución de Mayo, XVII Congreso Nacional de Arqueología Argentina (ed. por R. Bárcena y H. Chiavazza), Tomo V, pp. 1765-1770. UNCuyo-CONICET, Mendoza.

Giordano, A. y M. E. Gonaldi

1991 Manifestaciones del Arte Rupestre en una Zona de Alto Interés Turístico. Una Política de Protección. El Arte Rupestre en la Arqueología Contemporánea (ed. por M. M. Podestá, M. I. Hernández Llosas y S. F. Renard de Coquet), pp. 85-91. Buenos Aires.

Guráieb, A. G., M. M. Podestá, D. Rolandi y O. Damiani

2007 Estructuras prehispánicas de piedras del Parque Provincial Ischigualasto y su área de amortiguación, Prov. de San Juan. Actas XVI Congreso Nacional de Arqueología Argentina. Tras las huellas de la materialidad. San Salvador de Jujuy, 8 al 12 de Octubre de 2007. Tomo III, pp. 529-535. Jujuy.

Guráieb, A. G., M. Rambla y D. Carro

2010 Primera aproximación al estudio del registro lítico y cerámico del Parque Provincial Ischigualasto (PPI). Arqueología del Centro Oeste argentino: aportes desde las IV Jornadas Arqueológicas Cuyanas (ed. por R. Bárcena), pp. 91-105. XAMA Serie Monografías. INCIHUSA, Mendoza.

Hartley, R. y A. Wolley Vawser

1998 Spatial behavior and learning in the prehistoric environment of the Colorado River drainage (south-eastern Utah), western North America. The archaeology of rock art (ed. por C. Chippindale y P. Taçon), pp. 185-211. Cambridge University Press, Cambridge.

INAPL

2009 Los Colorados: un lugar para descubrir. AINA, Buenos Aires. 
Lochbaum, A. L. de 1993 Geomorfología del Alto de Ischigualasto, Valle Fértil, San Juan. Trabajo Final de Lic. en Ciencias Geológicas. FCEFN, UNSJ.

López, C. y A. García

2011 Arqueología y etnohistoria del centro-oeste argentino. Publicación de las VIII Jornadas de Investigadores en Arqueología y Etnohistoria del Centro-Oeste del País (comp. por C. M. Laferrerè, F. Ribero y J. Díaz), pp. 363-374. Universidad Nacional de Río Cuarto, Río Cuarto.

Mithen, S.

1996 Ecological Interpretations of Paleolithic Art. Contemporary Archaeology in Theory (ed. por R. Preucel y I. Hodder), pp. 79-96. Blackwell Publishers, Gran Bretaña.

Monetta, A. y C. Mordo

1995-1996 Ischigualasto-Talampaya. Tiempo de dinosaurios. Editorial Manrique Zago, Buenos Aires.

Morrone, J. J.

2005 Presentación sintética de un nuevo esquema biogeográfico de América Latina y el Caribe. Regionalización Biogeográfica en Iberoamérica y Tópicos Afines (ed. por J. Llorente y J. J. Morrone). Universidad Nacional Autónoma de México, México.

Nielsen, A.

2006 Estudios internodales e interacción interregional en los Andes circumpuneños: teoría, método y ejemplos de aplicación. Esferas de interacción prehistóricas y fronteras nacionales modernas: los Andes sur centrales (ed. por H. Lechtman), pp. 29-62. Instituto de Estudios Peruanos e Institute of Andean Research, Lima.

Pereyra, B. R.

2000 Clima de la provincia de San Juan. En Catálogo de recursos humanos e información relacionada con la temática ambiental en la región andina.

http://www.cricyt.edu.ar/ladyot/catalogo/cdandes/cap10.htm\#inhalt.

Consultado el 15 de junio de 2010.

Podestá, M. M., A. Re y G. Romero

2011 Visibilizando lo invisible. Grabados históricos como marcadores idiosincráticos en Ischigualasto. En ruta. Arqueología, historia y etnografía del tráfico sur andino (ed. por L. Núñez y A. Nielsen), pp. 341-372. Encuentro Grupo Editor, Córdoba.

Podestá, M. M. y D. S. Rolandi

2000 Sobre dinosaurios y marcas de ganado. Prospección arqueológica en Ischigualasto (Valle de la Luna-Provincia de San Juan). Novedades de Antropología. Boletín Informativo del INAPL 37: 3-6.

2001 Marcas en el desierto. Arrieros en Ischigualasto (San Juan, Argentina). Boletín de la Sociedad de Investigación del Arte Rupestre de Bolivia 15: 63-73. 
Podestá, M. M., D. Rolandi, A. Re, M. P. Falchi y O. Damiani

2006 Arrieros y marcas de ganado. Expresiones del arte rupestre de momentos históricos en el desierto de Ischigualasto. Tramas en la Piedra. Producción y usos del arte rupestre (ed. por D. Fiore y M. M. Podestá), pp. 169-190. SAA, INAPL, WAC, Buenos Aires.

Quinlan, A. y A. Woody

2003 Marks of distiction: rock art and ethnic identification in the Great Basin. American Antiquity 68 (2): 372-390.

Re, A.

2011 Representaciones rupestres en mesetas altas de la provincia de Santa Cruz. Circulación de información en espacios de uso estacional. Tesis doctoral. Facultad de Filosofía y Letras, Universidad de Buenos Aires. MS.

Re, A., M. M. Podestá y D. Rolandi

2009 Arte rupestre prehispánico en valles y quebradas del Parque Provincial Ischigualasto y de su área de amortiguación (Provincia de San Juan, Argentina). Crónicas sobre la piedra. Arte rupestre de Las Américas (ed. por M. Sepúlveda, L. Briones y J. Chacama). Ediciones Universidad de Tarapacá, Arica.

Riveros, M. G.

2010 Petroglifos de Colangüil (San Juan, Argentina). Publicaciones del Instituto de Investigaciones Arqueológicas y Museo 28 (nueva serie). Instituto de Investigaciones Arqueológicas y Museo, UNSJ, San Juan.

2011 Petroglifos de Conconta (San Juan, Argentina). Ponencia presentada a las IX Jornadas de Investigadores en Arqueología y Etnohistoria del Centro-Oeste del País. 24 al 26 de Agosto de 2011. Río Cuarto, Universidad Nacional de Río Cuarto.

Riveros, M. G. y A. del V. Varela

2001 Ischigualasto: estudio preliminar del arte rupestre. Publicaciones del Instituto de Investigaciones Arqueológicas y Museo 25: 131-147. Instituto de Investigaciones Arqueológicas y Museo, UNSJ, San Juan.

Rolandi, D., M. M. Podestá, G. Guráieb, A. Re y A. Vidal

2003 El patrimonio cultural en un área protegida de valor excepcional: Parque Provincial Ischigualasto (San Juan, Argentina). Relaciones XXVIII: 231-240.

Romero, G. y A. Re

2011 Arte rupestre y ocupaciones prehispánicas de la hoyada de Ischigualasto (provincia de San Juan). Ponencia presentada a las IX Jornadas de Investigadores en Arqueología y Etnohistoria del Centro-Oeste del País. 24 al 26 de Agosto de 2011. Río Cuarto, Universidad Nacional de Río Cuarto.

Sanchidrián Torti, J. L. y A. M. Márquez Alcántara

1998 Informe sobre la primera fase de intervención del Proyecto de Investigación. Documentación del arte rupestre de Ischigualasto (San Juan, Argentina) MS. 
Schaafsma, P. 1985 Form, content and function: theory and method in North American rock art studies. Advances in Archaeological Method and Theory 8: 237-277. Academic Press, New York.

Schobinger, J. y C. Gradin

1985 Arte rupestre de la Argentina. Cazadores de la Patagonia y agricultores andinos. Encuentro Ediciones, Madrid.

Suvires, G. M.

2000 Geomorfología de la provincia de San Juan. En Catálogo de recursos humanos e información relacionada con la temática ambiental en la región andina.

http://www.cricyt.edu.ar/ladyot/catalogo/cdandes/cap11.htm\#inhalt.

Consultado el 15 de junio de 2010. 